\title{
A review of current induction strategies and emerging prognostic factors in the management of children and adolescents with acute lymphoblastic leukemia
}

Saveria Capria, Matteo Molica, Sara Mohamed, Simona Bianchi, Maria Luisa Moleti, Silvia Maria Trisolini, Sabina Chiaretti \& Anna Maria Testi

To cite this article: Saveria Capria, Matteo Molica, Sara Mohamed, Simona Bianchi, Maria Luisa Moleti, Silvia Maria Trisolini, Sabina Chiaretti \& Anna Maria Testi (2020): A review of current induction strategies and emerging prognostic factors in the management of children and adolescents with acute lymphoblastic leukemia, Expert Review of Hematology, DOI: 10.1080/17474086.2020.1770591

To link to this article: https://doi.org/10.1080/17474086.2020.1770591

Accepted author version posted online: 18 May 2020.

Submit your article to this journal ๔

山 Article views: 14

Q View related articles $\widetilde{ }$

View Crossmark data 
Publisher: Taylor \& Francis \& Informa UK Limited, trading as Taylor \& Francis Group

Journal: Expert Review of Hematology

DOI: $10.1080 / 17474086.2020 .1770591$

\section{Review}

A review of current induction strategies and emerging prognostic factors in the management of children and adolescents with acute lymphoblastic leukemia

Saveria Capria ${ }^{1}$, Matteo Molica ${ }^{1}$, Sara Mohamed $^{1}$, Simona Bianchi ${ }^{1}$, Maria Luisa Moleti ${ }^{1}$, Silvia Maria Trisolini ${ }^{1}$, Sabina Chiaretti ${ }^{1}$ \& Anna Maria Testi ${ }^{1}$

1. Hematology, Department of Translational and Precision Medicine, 'Sapienza" University of Rome, Italy

Corresponding author:

Saveria Capria

Hematology, Department of Translational and Precision Medicine, Sapienza, University of Rome

Via Benevento 6, 00161, Rome, Italy

Tel.: +39-06-49974742

Fax: +39-06-44241984

Email: capria@bce.uniroma1.it 


\section{Abstract}

Introduction: Acute lymphoblastic leukemia is the most frequent hematologic malignancy in children. Almost $95 \%$ of children potentially achieve a complete remission after the induction treatment, but over the last years, new insights in the genomic disease profile and in minimal residual disease detection techniques have led to an improvement in the prognostic stratification, identifying selected patients' subgroups with peculiar therapeutic needs.

Areas covered: According to a comprehensive search of peer-review literature performed in Pubmed, in this review we summarize the recent evidences on the induction treatment strategies comprised in the children acute lymphoblastic leukemia scenario, focusing on the role of key drugs such as corticosteroids and asparaginase and discussing the crucial significance of the genomic characterization at baseline which may drive the proper induction treatment choice.

Expert opinion: Current induction strategies already produce durable remissions in a significant proportion of standard-risk children with acute lymphoblastic leukemia. A broader knowledge of the biologic features related to acute lymphoblastic leukemia subtypes with worse prognosis, and an optimization of targeted drugs now available, might lead to the achievement of long-term molecular remissions in this setting.

\section{Key words}

acute lymphoblastic leukemia, children, adolescents, induction strategies, minimal residual disease, dexamethasone, asparaginase, tyrosine kinase inhibitors 


\section{Article highlights box}

- The overall survival of children affected by acute lymphoblastic leukemia (ALL) is approximately $80 \%$, but some acute lymphoblastic leukemia subtypes (unfavorable genetic abnormalities, slow induction and consolidation response) show a lower cure rate.

- The identification of specific clinical/biological features influencing prognosis highlighted the significance of risk-adapted therapy.

- Dexamethasone has shown a greater antileukemic activity compared with prednisone in randomized trials. The use of dexamethasone induced a lower relapse-rate and better EFS especially in patients with T- acute lymphoblastic leukemia.

- Asparaginase is a key drug as part of induction treatment. By administering the appropriate doses, it is possible to determine an adequate asparagine depletion thereby ensuring an asparaginase activity.

- PEG-asparaginase might replace the use of native E. coli asparaginase because it is associated with a lower allergy and silent inactivation rate.

- $\quad$ AYA patients treated with high intensity pediatric or pediatric-like regimens show promising longterm outcome. In this age group (15-39 years), the allogenic transplant approach in first complete remission when minimal residual disease is low $\left(<10^{-4}\right.$ using a qPCR assay) is no longer recommended.

- In Philadelphia positive acute lymphoblastic leukemia, the current induction approaches comprising TKIs provide a high rate of negative minimal residual disease (MRD) achievement. The role of allogenic stem cell transplant remains an intriguing issue. The ongoing European Intergroup of patients with Philadelphia positive ALL/Children's Oncology Group (EsPhALL2017/COGAALL1631) study restricts transplant indications to patients with poor MRD response (EudraCT No.: 2017000705-20).

- Philadelphia-like acute lymphoblastic leukemia is a current treatment challenge among children and adolescents. The standardization of diagnostic technologies is still ongoing and the treatment role of tyrosine kinase inhibitors and Janus kinase inhibitors in this setting is currently under investigation.

- The outcome of acute lymphoblastic leukemia in Down syndrome children is worse, compared with the general pediatric population mainly due to the therapy-related toxicities and higher relapserate. Further strategies including better supportive care, reduced intensity regimens in some low risk patients, and novel immunomodulating agents might improve the outcome of these patients.

- Acute lymphoblastic leukemia in infants is a very rare event, with unfavorable prognosis probably related to the high frequency of KMT2A gene rearrangements and overexpression of fms-like 
tyrosine kinase 3 . The suitable treatment modalities in this setting are still debated. A broader knowledge of the biological profile is warranted to identify the proper therapeutic strategy.

\section{Introduction}

Acute lymphoblastic leukemia (ALL) is the most common type of cancer in children, and current treatments offer a good chance for a cure. In fact, thanks to the therapeutic innovations implemented over the last years, the overall survival (OS) reached approximately $80 \%$ in this setting, with certain experiences reporting cure rates greater than 98\%[1-4]. These prominent advances in treatment have led not only to improvements in outcome, but have also highlighted the significance and the critical need of clinical trials conducted by cooperative multicenter groups.

Childhood ALL avails as a paradigm for risk-adapted therapy; the stratification of therapy intensity markedly depends on the risk-rate of treatment failure. By identifying the features potentially influencing prognosis, patients can be stratified into several groups according to the treatment-failure risk[5-7]. Several clinical characteristics, including age less than 1 year and older than 10 years, white blood cell count (WBC) greater than 50.000-100,000/ul and the involvement of sanctuary organs at baseline have widely been associated with an increased risk of disease failure. Historically, the $T$ immunophenotype was considered to be an unfavorable prognostic feature, but with the contemporary treatment regimens, the outcome of T-cell ALL (T-ALL) and, of the more recently identified early T-precursor (ETP) ALL, has improved and has become similar to B-lineage ALL. [8,9]. Furthermore, recurrent cytogenetic abnormalities detected in the leukemic blast allow a molecular risk-stratification, with certain markers related to favorable (hyperdiploidy, ETV6/RUNX1) and unfavorable (hypodiploidy; $B C R-A B L$ fusion, KMT2A rearrangements) outcome[1-4]. In addition, the hematologic response to the early treatments has emerged as an independent prognostic predictor. The assessment of bone marrow minimal residual disease (MRD) detected by polymerase chain reaction (PCR) and/or flow cytometry ( $F C M)$, during and after induction has also proved to be an independent factor able to significantly predict outcome. The application of these clinical and biological risk stratifications by the various pediatric oncology cooperative groups [Children's Oncology Group (COG); Associazione Italiana di Ematologia e Oncologia Pediatrica (AIEOP); Berlin-Franklin-Münster (BFM) Group; St Jude Children's Research Hospital (SJCRH); United Kingdom (UK) Medical Research Council (MRCUKALL)] has led to treating children with favorable features with less intensive regimens, and reserving aggressive approaches for those with high-risk characteristics[6,10-13].

Although some cooperative groups still base their induction strategy on age and WBC at initial diagnosis, MRD measurement has become the strongest prognostic indicator in pediatric ALL, blurring the importance of other historical prognostic factors.(T-ALL, ETP) $[8,10,12,14,15$. 
The risk-stratification, however, did not affect the type and/or intensity of the induction treatments excluding a limited number of children such as those with $B C R-A B L$ fusion transcript who currently receive tyrosine kinase inhibitors (TKIs) combined with chemotherapy and infants where novel intensive therapeutic approaches are being carried out[11]. Furthermore, some experiences have been conducted with the aim of de-intensifying induction treatments in a small group of children defined, at disease onset, as very low-risk (patients with both favorable clinical and biological features and early response to chemotherapy)[16]. However, treatment intensity after induction, is adjusted according to MRD results. Therapy de-intensification is feasible for those children who have a low risk of relapse on the basis of rapid MRD clearance by the end of induction therapy $[15,17]$.

\section{Induction therapy}

The induction phase is the first chemotherapy approach in children with ALL, lasting 4 to 6 weeks. The goal of induction is attaining a complete remission (CR), with more than $95 \%$ of children with ALL potentially achieving this benchmark[2,3,4]. Induction failure, defined by the persistence of leukemic blasts in blood, bone marrow, or any extramedullary site after 4 to 6 weeks of remission induction therapy, occurs in 2 to $3 \%$ of patients and represents one of the most unfavorable outcomes in pediatric ALL. In an extensive retrospective study including 1041 patients from 14 cooperative study groups, Schrappe et al. identified several high-risk features frequently associated with treatment failure: older age, high leucocyte count and 11 q23 rearrangement. In this patient population the 10 -year survival rate is estimated at only $32 \%[18]$.

The agents currently used during induction include vincristine, corticosteroids, and asparaginase, with many regimens adding an anthracycline ( daunorubicin or doxorubicin, idarubicin, epirubicin, mitoxantrone). All anthracyclines showed comparable efficacy and toxicity in randomized trials[19,20]. Anthracycline therapy has been used in childhood ALL since the 1960s, and likely contributed to the increase in the 5 -year survival rate from $30 \%$ to over $70 \%$. However, the most serious adverse effect of anthracyclines therapy is their cardiotoxicity[21]. The emergence of this problem has led to the development of strategies aimed at reducing cardiac adverse effects while maintaining efficacy against the disease (cardioprotective therapies during treatment, different anthracyclines' derivatives or different infusion schedules). So far, the only independent risk factor identified for cardiotoxicity, is the cumulative dose more than $300 \mathrm{mg} / \mathrm{m}^{2}$. Certain groups spare the addition of anthracyclines to patients with low-risk disease in an attempt to reduce short- and long-term toxicities. In the past years, the AIEOP ALL 95 study provided for standard risk (SR) patients (favorable WBC count, age and DNA index), a reduced intensity induction treatment (prednisone, vincristine and asparaginase- mainly Erwinia products). Event-free survival (EFS) in this highly selected subgroup (6.6\% of patients) was not satisfactory $(85.0 \%( \pm 3.4)$ at 10 years), although most relapses could be rescued by salvage therapy resulting in a survival probability of $94.5 \%( \pm 2.2)$ at 10 years. In this protocol, MRD was not measured at the end or during induction[22]. More 
recently, the COG AALL0331 trial, elected to treat SR patients with a 3-drug induction (vincristine, dexamethasone and asparaginase) and allocate intensive post-induction therapy based on risk of relapse, defined by genetic abnormalities and early response to therapy (bone marrow morphology at day 8 and day 15 and end-induction MRD). Three subgroups were identified (low, average and high-risk); the 6-year overall survival (OS) rate for more than 5000 children with SR ALL exceeded 95\%[17]. These results suggest that improving post-induction patients' stratification, may reduce the relapse rate, and on the other hand, a subset of SR children can be spared the toxicities associated with more intensive therapy without compromising a survival benefit[17]. Other studies have suggested that intensive induction therapy is unnecessary for children with SR ALL, provided patients receive postinduction therapy modulated on MRD response[23,24]. However, a 4-drug induction is still used for SR children in the BFM and BFM-like protocols and it is mandatory, for major multicenter groups, in children in the high-risk group. Daunorubicin is the most commonly used anthracycline with a cumulative induction dosage of $75-120 \mathrm{mg} / \mathrm{m}^{2}$.

\subsection{Vincristine}

Vincristine is a core chemotherapeutic agent for patients with ALL. Vincristine was first reported to be an active agent in 1962, when it was studied as single-agent therapy in 13 patients with acute leukemia. In this study from the National Cancer Institute (NCI), 54\% of patients achieved CR. In the mid-1960s, the group at SJCRH, incorporated vincristine into the sequential childhood ALL protocols. Following bolus intravenous administration, peak plasma concentration is briefly achieved in children, with a rapid cellular uptake and extensive tissue binding of the drug[25]. Clearance values for children are generally greater than those for infants and adults; it is still not certain if vincristine clearance decreases with age during childhood[26]. Unfortunately its use is associated with more than $70 \%$ of Vincristine Induced Peripheral Neuropathy (VIPN), characterized by progressive motor, sensory and autonomic damage which impairs children's quality of life[27,28]. This complication often leads to dose reduction, decreasing therapeutic efficacy, but it does not seem dose-related, as vincristine is usually administered at a maximum fixed dose of $2 \mathrm{mg}$ regardless of body surface area.

It is not yet well known why some patients develop a greater neurologic impairment, but pharmacogenomic studies have shown that some allelic variants of CYP3A5 are associated with worse drug catabolism. Other factors have also been linked to vincristine neurotoxicity, such as diabetes, hypertriglyceridemia and obesity[29].

\subsection{Glucocorticoids}

Over the years, glucocorticoids have been a cornerstone of induction regimens in pediatric ALL. Historically, prednisone has been the most common glucocorticoid used during induction, whereas dexamethasone has been applied during the re-intensification phase. Dexamethasone has a six- to seven-fold higher efficacy 
than prednisone in terms of anti-inflammatory activity, which traditionally led to dexamethasone/prednisone equivalent dosages of $1: 6$ to $1: 7[30]$. The in vitro data on the relative antileukemic efficacy of dexamethasone and prednisone suggest a 16-fold higher median cytotoxic activity of dexamethasone, despite a large inter-individual variability[31]. Additional factors may confer a greater in vivo efficacy to dexamethasone compared to prednisone; a longer plasma half-life and a lower proteinbound fraction in combination with a longer half-life in the cerebral spinal fluid (CSF), leading to better CSF penetration and higher CSF concentrations[32]. Therefore, some clinical trials have reported superior outcomes using dexamethasone instead of prednisone during induction treatments, probably due to a lower rate of central nervous system (CNS) relapses[16,33]. SR children treated with CCG 1922 protocol, were randomly assigned to receive dexamethasone $\left(6 \mathrm{mg} / \mathrm{m}^{2} / \mathrm{d}\right)$ for 28 days in induction, compared with prednisolone $\left(40 \mathrm{mg} / \mathrm{m}^{2} / \mathrm{d}\right.$ ); 6-year isolated CNS relapse rate was $3.7 \%$ vs $7.1 \%$ for dexamethasone and prednisolone arm, respectively[34]. The MRC-UK ALL97 randomized trial, assigned children with newly diagnosed ALL, to receive dexamethasone or prednisolone, in the induction, consolidation and continuation phases of treatment. Among 1603 eligible randomized patients, those receiving dexamethasone had half the risk of isolated CNS relapse; EFS was significantly improved with dexamethasone $(84.2 \%$ vs. $75.6 \%$ at 5 years; $P=0.01$ ), with no evidence of differing effects in any subgroup of patients[35]. The randomized COG AALL0232 trial enrolled newly diagnosed high-risk B-ALL who received dexamethasone (14 days) versus prednisolone ( 28 days); dexamethasone given during induction benefited younger children but provided no benefit and was associated with a higher risk of osteonecrosis among participants 10 years and older[36]. In the randomized AIEOP-BFM ALL 2000 trial, children received induction prednisone $\left(60 \mathrm{mg} / \mathrm{m}^{2} /\right.$ day $)$ vs dexamethasone (10 mg/m²/day) after a common 7-day prednisone pre-phase[37]. Between 2000 and 2006, among the 4937 patients registered in the trial, 3720 were eligible for randomization. The proportion of patients who did not achieve a CR on day 33 (end of induction phase; IA) was similar in both the randomized groups. Among patients with precursor B-ALL, a faster MRD response was observed on day 33 in the dexamethasone group; the difference was no longer on day 78 (end of phase IB)[37]. In 5-6\% of T$A L L$, there was also a shift toward lower MRD levels in the dexamethasone arm, which was apparent on day 33 and day 78, but was not statistically significant. (Table 1). Moreover, among T-ALL patients showing a pre-phase prednisone good-response, a significantly lower relapse rate and a better EFS, were reported in the dexamethasone arm[37]. However, the greater anti-leukemic activity of dexamethasone corresponded to a significantly higher incidence of induction-related life-threatening events and deaths (bacterial and fungal infections), which diminished but did not eliminate its favorable effect on EFS. Although the EFS was significantly better for patients randomized in the dexamethasone arm (hazard ratio [HR], 0.85 [0.73-0.98]), no difference was observed between the two groups with respect to OS (HR, 1.05 [0.87-1.27])[37].

. As part of intensifying therapy, multiple other groups have compared different corticosteroids regimens. T-ALL patients treated on UKALL2003 had significantly improved survival compared to previous trials 
UKALL97/99 (3-year OS 90\% vs 78\%); one of the major modifications between the trials was the use of dexamethasone as the only corticosteroid for all patients[14,23]. The benefit of dexamethasone over prednisone in pediatric T-ALL, was also reported by SJCRH[24]; dexamethasone-based induction was employed in order to eliminate cranial radiotherapy (CRT) for most patients. Induction therapy with dexamethasone did not improve T-ALL EFS compared to prednisolone in those trials where CRT was part of the treatment (European Organization for Research and Treatment of Cancer Children's Leukemia Group EORTC-CLG 58881 and 58951 trials[38].

\subsection{Asparaginase}

Asparaginase constitutes an established treatment for ALL, exploiting a key weakness of ALL cells, their inability to synthesize asparagine. $[39,40]$. Several different agents for asparagine depletion are currently available, deriving from two different bacterial sources: Escherichia coli and Erwinia chrysanthemi. Native asparaginase and PEGylated asparaginase (PEG-asparaginase) both derive from E. coli, while crisantaspase results from Erwinia chrysanthemi. All types of asparaginase share the same mechanism of action. However, due to the differences in the pharmacokinetic properties the three agents are not interchangeable at the same dose and frequency. Asparaginase activity peak levels should be at least 100 IU/I in order to achieve a depletion of plasma asparagine to less than $0.1 \mathrm{mmol} / \mathrm{l}$, which confers an optimal therapeutic effect[40-42].

Two studies conducted in the 1990s compared the native E. coli asparaginase and crisantaspase using identical dosing schedules in pediatric ALL. The Dana Farber Cancer Institute DFCI-ALL Consortium Protocol 95-01 randomized 491 children aged less than 18 years to crisantaspase or native E. coli asparaginase at a dose of $25000 \mathrm{IU} / \mathrm{m}^{2}$ intramuscularly (i.m.) once during induction (day 4) and thereafter. Crisantaspase was associated with an inferior 5-year EFS compared with native E. coli asparaginase (78.4 vs 89.3\%, $p<0.01)[43]$. The EORTC-CLG 58881 trial randomized 700 children with ALL or lymphoblastic lymphoma, to

receive either native $E$. coli asparaginase or crisantaspase at a dose of $10000 \mathrm{lU} / \mathrm{m}^{2}$ intravenously (i.v.) twice weekly. A higher proportion of patients in the crisantaspase group did not achieve a CR compared with the native $\mathrm{E}$. coli asparaginase cohort (4.9 versus $2.0 \%, p=0.038$ )[44]. The native $\mathrm{E}$. coli asparaginase was also associated with longer EFS in the subgroup of T-ALL[45]. These studies highlighted the significance of using the appropriate doses of this crucial induction drug, thereby ensuring an adequate asparaginase activity and sustaining asparagine depletion (Table 1).

In common with all large proteins, asparaginase has also the capacity to elicit an immune response resulting in the development of anti-asparaginase antibodies; this represents the main reason of resistance to asparaginase and results in a decreased efficacy of the drug conferring an adverse clinical outcome to children with ALL[46-48]. The occurrence of anti-asparaginase antibodies is rare during the induction phase, while it is more frequently observed at drug re-exposure (consolidation or re-induction phase). The 
asparaginase resistance can be symptomatic, with signs of clinical hypersensitivity, or asymptomatic without any apparent signs (silent inactivation). The published rates of clinical hypersensitivity vary greatly between the studies, due to differences in dosing, route of administration, duration of treatment, concomitant medication and the asparaginase preparation used in treatment. The hypersensitivity rates to native E. coli asparaginase are higher (9-75\%), compared with those reported with either PEG-asparaginase $(4-8 \%)$ or crisantaspase (3-37\%)[49]. Furthermore, it was reported that crisantaspase and PEGasparaginase may be associated with a lower rate of antibody development than native E. coli asparaginase[46-50]. The antibody rates with native E. coli asparaginase $\left(5000 \mathrm{lU} / \mathrm{m}^{2}\right.$ i.v. every 3 days for eight doses in induction) were about $40 \%$, the rates observed with PEG-asparaginase ranged from 11 to $18 \%$ and the rates with crisantaspase varied from 8 to $21 \%$ depending on the schedule and the dose[39].

The PEG-asparaginase, modified by covalent attaching polyethylene glycol, results in a longer half-life and decreased immunogenicity and is increasingly used as frontline in clinical practice. Several randomized trials have reported superior efficacy of this PEGylated formulation. In CCG protocol 1962, 118 children with SR ALL were randomized to receive native or PEG-asparaginase as part of induction; a faster clearance of bone-marrow lymphoblasts and a longer asparaginase activity were reported in those treated with PEGasparaginase. The adverse events, infections, and days of hospitalization were similar in the two arms[46]. In the AIEOP-BFM ALL 2009 trial includeding i.v. PEG-asparaginase in induction, the clinical allergy and silent inactivation were lower compared with the previous trials, which provided the native E. coli asparaginase product; severe side effects remained unchanged. These studies recommended that PEG-asparaginase might replace the native form in frontline treatments of pediatric ALL.

Although there is a cross-reactivity between asparaginases derived from E. coli, the crisantaspase does not display this in either form of E. coli-derived asparaginase and allows patients to maintain treatment duration, if given at the appropriate dose and schedule. Consequently, several trials, such as the AIEOPBFM ALL 2009, identified crisantaspase as the second-line asparaginase agent using for the treatment of patients with an allergic reaction or silent inactivation during frontline treatment with PEG-asparaginase[8]. According to the results of various trials and considering the regulatory standards and availability, the crisantaspase may be used as a viable second-line therapy in this setting. Further data indicated that the crisantaspase administration should be at doses of at least $20000-25000 \mathrm{IU} / \mathrm{m}^{2}$ on alternate days (or three times weekly) by either the i.v. or the i.m. route[40,41].

\section{Minimal Residual disease (MRD)}

Response to chemotherapy is the strongest prognostic indicator in pediatric ALL, and several studies confirmed the prognostic importance of the clearance of leukemic blasts in the early phase of treatment $[6,12,51,52]$. The number of blasts in peripheral blood at day 8 , the percentage of residual blasts in bone marrow at day 15 , have been widely used to deliver risk-directed therapy, and most study groups 
modified treatment according to these risk indicators[6,12,51-54]. However, the further use of "in vivo prednisone response"(peripheral leukemic cells $<1000 / \mu \mathrm{l}$ after 7-day prednisone-prehase) originally described by the BFM group, although cheap and universally accessible, is hampered by limited sensitivity and specificity for the current treatment strategies.

In recent years, technological progress has enabled us to detect MRD; PCR amplification targeting leukemia-specific T-cell receptor/Immunoglobin (TCR/Ig) can detect as few as $0.001 \%$ of residual leukemic cells. FCM can also identify residual leukemic cells using a combination of leukemia associated surface markers. The FCM detection threshold is $0.01 \%$, but it is faster, less expensive, and applicable as a complement to PCR-MRD[52,55]. By using both PCR and FCM, SJCRH showed that MRD kinetics were able to be assessed in $>99 \%$ of ALL cases. Multiple studies have shown that MRD status is significantly predictive of relapse risk[12,53,54]. In the AIEOP-BFM-ALL 2000 study, FCM MRD was measured in a large fraction of patients at day 15 to evaluate the prognostic impact[37,51]. Those children achieving $<0.1 \%$ bone marrow residual blasts had an excellent treatment outcome with more than $90 \%$ of them remaining relapse free after 5 years. Randomized study by UKALL2003 showed that intensification for residual MRD was able to improve EFS, while reduction of therapy was possible for a group defined as low risk by MRD status[14]. The AIEOP-BFM ALL 2000 study used MRD measurements by PCR at the end of induction (phase IA; day 33) and at the end of induction consolidation (phase IB; day 78). Negative MRD at day 33 remained a predictor of a better treatment outcome in both T-cell and B-ALL, while negative MRD at day 78 was more predictive of favorable outcome of T-cell than B-ALL[6,7]. In the SJCRH Total therapy 15 study, MRD was measured by FCM and/or PCR on day 19 and day 46 of remission induction therapy. All patients with MRD $\geq 1 \%$ at day 19, (including hyperdiploid, NCl-standard risk and T-ALL) had a significantly worse outcome (cumulative relapse risk $26.6 \%$ vs $7.6 \%$ ). Among patients with negative MRD at day 19 , those with ETV6-RUNX1 or hyperdiploidy ALL had a particularly low relapse risk (1.9\%), suggesting that these forms of ALL could receive treatment reduction strategies to improve quality of life. Outcome was especially poor among patients with $M R D \geq 1 \%$ on day 46 , who had EFS of $50 \%[13,56]$. Similarly, in the COG AALL0232 study, the 5year EFS for patients with MRD level between $1 \%$ and $<10 \%$ at the end of induction, was only $44 \%$ and $26.5 \%$ for those with $M R D \geq 10 \%[36]$.

Serial monitoring of MRD is also important for those patients still positive at the end of remission induction; some of them may be cured with chemotherapy alone if MRD becomes undetectable after subsequent treatment. In particular, in ETP ALL which is generally associated with high levels of MRD during and after remission induction therapy, recent studies (AIEOP-BFM) suggest that postremission chemotherapy might be effective in reducing MRD and could mitigate an adverse prognosis[8]. In B-lineage ALL, MRD continued to be prognostically important, especially in patients with some high-risk subtypes. The outcome of children with hypodiploid ALL, usually dismal, can be improved by MRD-guided therapy; those with negative MRD at the end of induction are curable with intensive chemotherapy; for the other, HSCT, in first remission, could 
improve the prognosis. Patients with Ph-like ALL with poor initial treatment response can be salvaged with MRD-based directed therapy and may benefit from identification of kinase-activating lesions for target therapies[53,57]. Persistent MRD after consolidation treatment predict a dismal prognosis if treatment consists of chemotherapy alone, and has been used as an indication for allogeneic HSCT. L

\section{CNS prophylaxis and/or treatment}

A further issue in treating ALL pediatric patients is the targeted therapy for CNS involvement. This approach constitutes a paramount part of the induction phase and includes either the treatment of patients with documented CNS disease at diagnosis, or the prophylaxis for patients with subclinical disease. The significance of this part of treatment was evident before the 1970s, when induction regimens lacked of this component. In fact, although the bone marrow remission could be achieved using systemic chemotherapy, most children eventually developed CNS relapse due to the lack of specific treatments directed toward this sanctuary site[58].

There are several approaches aimed at eradicating disease from the CNS, including direct intrathecal (IT) administration of drugs, systemic chemotherapy able to penetrate the blood-brain barrier, and cranial radiation (CRT). All children with ALL receive an intrathecal chemotherapy at the beginning and during the induction phase. The options for IT chemotherapy are methotrexate, as single agent or a combination of IT methotrexate, cytarabine, and hydrocortisone (known as triple intrathecal, ITT). No significant differences have been demonstratedbetween the two approaches, in terms of OS and EFS, although some evidence of a lower rate of CNS relapse with the use of ITT has been reported[59].

In this regard, the CCG 1952 trial for the treatment of standard risk pediatric ALL, compared IT methotrexate with ITT as CNS prophylaxis. The 6-year EFS with ITT or IT methotrexate were the same (80.7\% vs $82.5 \%$ ); the cumulative incidence of isolated CNS relapse was lower in the ITT group (3.4\% vs $5.9 \% ; p=0.004)$ but a higher number of bone marrow and testis relapses, poorly responding to salvage therapy, were reported in the ITT group. It appeared that ITT improved pre-symptomatic CNS treatment but did not benefit OS[59].

The CNS prophylaxis during the induction phase requires at least three doses of intrathecal therapy, while five doses are recommended for those children with CNS involvement at baseline. The high doses of systemic chemotherapy are not usually incorporated in the induction regimens, but used in course of consolidation or delayed intensification. However, an intensified induction with cyclophosphamide $\left(1 \mathrm{~g} / \mathrm{m}^{2}\right)$ and high-dose methotrexate $\left(5 \mathrm{~g} / \mathrm{m}^{2}\right)$, administered at the beginning of phase $\mathrm{IA}$, was included in the EORTC-CLG 58951 trial in pediatric T-ALL. A moderate outcome improvement was observed (8-year EFS $76.6 \%$ vs $71.6 \%$ of the previous not intensified 58881 trial), but, isolated or total CNS relapse rate was not 
decreased. Only T-ALL prednisone good responder (PGR) patients had better outcome (8-year EFS $84.6 \%$ vs $75.3 \%)[45]$.

Current trials are increasingly focused to omit CRT with the aim to prevent the severe long-term sequelae frequently associated to this procedure The SJCRH Total Therapy Study 15 and the Dutch Childhood Oncology Group protocol ALL-9 were the first to remove prophylactic CRT, using instead intensive systemic chemotherapy and ITT[56,60]. In the SJCRH Total Therapy protocol 15, patients were also randomized to receive an optional therapeutic window with upfront methotrexate over 4 or 24 hours.; no significant difference in the outcome was observed between randomized and no-randomized patients. The aim of the SJCRH Total Therapy Study 16, was to improve EFS and CNS control, by refining risk-directed therapy and intensifying systemic and intrathecal chemotherapy without CRT[61]. Higher doses of PEG-asparaginase failed to improve the outcome (5-year continuous CR rate $90.4 \%$ vs $91.2 \% ; p=0.91$ for higher vs standard PEG-asparaginase dose, respectively), but additional intrathecal therapy during early induction seemed to improve CNS control without excessive toxicity for high-risk patients. Despite the omission of CRT, the rates of isolated CNS relapse or any CNS relapse were $1.5 \%$ and $1.8 \%$, respectively, significantly lower than the 4.0\% and $5.7 \%$ respectively, observed among the historic controls treated in the previous Total Therapy Study 15[61].

\section{Adolescents and Young Adults}

In 2006, the National Cancer Institute Adolescent and Young Adult Oncology Progress Review Group identified adolescent and young adult (AYA) patients with ALL, ranging in age between 15 and 39 years, as a unique subgroup with specific characteristics and needs[62,63]. Although $>80-90 \%$ of children with ALL are cured of their disease, outcomes historically were much poorer for AYAs, with EFS ranging from 30 to $45 \%$ and survival appeared to plateau in the 1990s[64-68]. The most significant reason that could account for this disparity in outcomes is that ALL in AYAs has different biology from ALL in children, as leukemia cells in older patients typically have more genetic alterations.

The main difference is the higher proportion of patients with BCR-ABL1, KMT2A, and IGH translocations that predict poor prognosis and outcome $[5,69,70]$. Similarly, there are fewer patients with genetic alterations that portend a favorable prognosis, including hyperdiploidy and ETV6-RUNX1 translocation[69,70]. Furthermore, intrachromosomal amplification of chromosome 21 (iAMP21), is more frequent in AYAs with ALL [71]. This abnormality has been associated with a higher risk of relapse only partially diminished by intensified treatment $[72,73]$. The AYA patients also have a higher proportion of ETP[74]. The prevalence of immature T-ALLs increases with age, from $8 \%$ in children to $35 \%$ in adults $[9,69,75]$.

Retrospective analyses over the past 15 years have shown that the 5- and 7-year OS of AYA patients has significantly improved with pediatric-like or even fully pediatric approaches rather than adult treatment 
induction modalities, with long-term survival rates of almost 70\%[76-89] (Table 2). These improvements in outcome have challenged allogeneic hematopoietic stem cell transplant (HSCT) indications in first remission, in this population.

Disparities in chemotherapy or dose-intensity are the main differences between these two approaches. Higher cumulative doses of vincristine, asparagine and steroids, as well as more intensive CNS prophylaxis, were characteristic of pediatric protocols, whereas higher doses of cytarabine were used in in adult trials[80,82-86].

Multicenter adult ALL studies have adopted pediatric trials in AYAs up to the age of 40. The Spanish Programa Espanol de Tratamientos en Hematologia was the first group to report on the outcome of 81 patients (15-30 years) with standard risk Philadelphia negative (Ph)-ALL treated with the pediatric ALL-96 study[80]. In this protocol, the 6-year EFS and OS were $61 \%$ and $69 \%$. Since then, multicenter cooperative ALL groups[81,87] have demonstrated the feasibility and effectiveness of pediatric regimes for AYA patients. Recently, the CALGB reported the results of the 10403 trial, whose doses and schedule were identical to pediatric COG AALL0232-high risk-protocol; the estimated 3-year EFS and OS were 59\% and $73 \%$, respectively[86]. All of these studies provided evidence that extensive use of glucocorticoids, vincristine and PEG-asparaginase could result in a survival benefit for AYA patients with ALL. Asparaginase use in AYA patients has historically been limited because of the perception of an increased risk of toxicity with age (grade 3-4 hepatic and pancreatic adverse events; venous thromboembolic events, osteonecrosis)[90]. Lower doses of asparaginase are also used in some AYA protocols, in part to reduce the risk of toxicity[90-95].

Minimal residual disease status at the end of induction therapy has also been associated with survival differences in AYAs[96,97]. Compared with children, adults with B-cell ALL are slower to achieve MRDnegative status[96]. In 2009, a large Italian study first reported that MRD analysis during early postremission therapy improves risk definitions and bolsters risk-oriented strategies. The authors demonstrated that molecular analysis of MRD performed with at least one sensitive probe during the first months of induction/consolidation therapy is an unrivalled early prognostic indicator in unselected adult patients with standard-and high-risk ALL and confirmed its applicability in $80 \%$ or more of cases, thus improving clinical risk classification[96].

Data incorporating MRD-based prognostic assessments suggest that there is no benefit to allogeneic transplant in first CR compared with consolidation chemotherapy when MRD levels prior to transplant are low $\left(<10^{-4}\right.$ using a qPCR-based assay)[98-100].

However, not all the adult induction regimens have had inferior outcomes compared with pediatric therapies in AYA patients with ALL. Adult protocols that contain the backbones of pediatric therapy, including intensification MRD-driven induction phases, CNS prophylaxis, and prolonged maintenance, induce similar results compared with purely pediatric based therapy[86]. 


\section{Philadelphia positive $(\mathrm{Ph}+) \mathrm{ALL}$}

About $3-5 \%$ of pediatric patients with ALL harbor the $t(9 ; 22)(q 34 ; q 11.2)$ translocation, commonly known as the Philadelphia chromosome and resulting in the fusion product BCR-ABL. Historically, this ALL subtype resulted in poor prognosis with low remission rate and long-term EFS of about $30 \%$ after conventional chemotherapies[101-103]. In this setting, the HSCT in first CR was associated with superior EFS. When TKIs (imatinib) became available, initially for adults and then for pediatric patients, the European Intergroup of patients with Ph+ ALL designed the EsPhALL2004 protocol (2004-2009) investigating a post-induction treatment with imatinib in all high-risk patients and at random in good-risk patients. This trial showed a $10 \%$ advantage in disease-free survival (DFS) for the use of imatinib after the induction phase[104]. Other current studies in pediatric age showed benefits from continuous protracted exposure to imatinib. In the COG AALL0031 study, continuous imatinib exposure (340 mg/m $\mathrm{m}^{2}$ per day) improved outcome, with no significant toxicities and a 3-year EFS of $80 \%$, which was markedly better than historical controls treated without TKIs (35\%), [105]. These results were confirmed by the SJCRH experience, which incorporated TKIs in induction therapy on day 22. TKIs produced a marked drop in MRD level; at the end of remission induction, 9 out of 11 patients treated with imatinib or dasatinib and conventional induction chemotherapy achieved MRD-negative status, compared to only 2 out of 16 patients treated with chemotherapy alone $(p<0.001)$. The 5 -year EFS were $68.6 \%$ versus $31.6 \%$ in patients who received TKIs versus those who did not[106]. These studies suggested that TKIs administered in the early phases of chemotherapy might dramatically decrease MRD levels, improve the outcome of childhood Ph+ ALL and challenge the indications to HSCT.

In 2010, the EsPhALL trial was amended so that all patients received imatinib continuously from day 15 of induction. Induction-phase chemotherapy was done according to national or study group protocols and mainly consisted of vincristine, anthracycline, prednisone and asparaginase. One hundred and fifty-five children were enrolled in the study; the early exposure to imatinib improved the response to induction therapy (CR rate was $97 \%$ vs $78 \%$ of EsPhALL2004 study). The MRD was assessed by real-time quantitative PCR of rearranged Ig or TCR genes of mononuclear bone marrow cells collected at specified time-points. . At the end of induction, 27 (33\%) patients were MRD negative and 55 (67\%) were MRD positive[11]. The continuous exposure to imatinib clearly delayed the time of relapses in Ph+ ALL, but a plateau in EFS for non-transplanted patients has not yet been achieved. The relapse-risk was low in patients with early negative MRD who received a HSCT.

However, imatinib given early and continuously with intensive chemotherapy, was associated with severe toxicity. The toxicity observed in this study warrants further investigations on the efficacy of less intensive chemotherapy associated with early and protracted exposure to imatinib, in the role of transplant and in immunological innovative approaches for these patients. Whether giving second-generation ABL-class TKIs, 
such as dasatinib in conjunction with intensive chemotherapy, may further improve outcomes in this setting, is currently being investigated[107]. Other questions regard the optimal CNS therapy in these patients at high risk of CNS involvement. CNS treatment should include the use of intrathecal therapy from the early phases of therapy and high-doses of systemic chemotherapy should be included in the consolidation phase.

The $\mathrm{Ph}+\mathrm{ALL}$ is also relatively rare in AYAs $(<20 \%)$. The outcomes of these patients were unfavorable until the introduction of TKIs, which provide survival rates very close to those documented in Ph- ALL when they are administered, either alone, or in combination with chemotherapy, and followed by allogeneic HSCT. In particular, with the use of the third generation TKI ponatinib, survival rates close to $80 \%$ have been reported, even sparing the post-remission HSCT option in some patients[108]. Recently the COG reported comparable results in non-transplant and transplant patients with a chemotherapy-dasatinib combination trial including AYAs (1-30 years) (Table 3)[107]. Moreover, the Gruppo Italiano Malattie Ematologiche dell'Adulto (GIMEMA) cooperative group proposed the D-ALBA trial for $\mathrm{Ph}+\mathrm{ALL}$ older than 18 years with the aim of decreasing the chemotherapy burden thereby reducing toxicities. This study including induction TKI monotherapy followed by consolidation with Blinatumomab administration, leads to 1-year-OS and DFS rates of $94.8 \%$ and $87.8 \%$, respectively[109].

\section{Ph-like ALL}

Recently, independent research groups have identified a new subtype of B-ALL called Ph-like[110-112]. From a clinical standpoint Ph-like patients are more frequently male gender, young adults, and are characterized by a worse outcome due to an inferior response to induction therapy, a higher incidence of relapse and a lower survival (approximately $60 \%$ at 5 years) compared to the remaining B-ALL BCR/ABL1 negative cases[111].

Although the high heterogeneity at presentation and the frequent difficulties to make a proper diagnosis due to the current lack of standardized approaches, the Ph-like ALL constitutes up to $15 \%$ of childhood BALL and $20 \%$ to $25 \%$ of AYAs ALL. The methods of classification employed can partially explain the various incidence reported by some groups, which may also reflect differences in study cohorts (age, ethnicity, reference group)[113,114].

The leukemic cell gene expression profile of Ph-like ALL is similar to that of Ph+ ALL, but it is a genetically heterogeneous disease. Approximately half of these patients harbor abnormalities of the cytokine receptor gene CRLF2 and concomitant activating mutations of the Janus kinase genes JAK1 or JAK2, resulting in activation of JAK-STAT signaling[115]. Patients without CRLF2 rearrangements commonly harbor a disease array of genetic alterations that activate cytokine receptor and tyrosine signaling. Moreover, similar to $\mathrm{Ph}+$ ALL, Ph-like ALL is characterized by a high frequency of alterations of the IKZF1 gene, which encodes the 
early lymphoid transcription factor IKAROS[110]. Thus, the genomic characterization has significant therapeutic implications in Ph-like ALL, and some reports are emerging with the use of TKIs and JAK inhibitors in this patient population[116,117]. Also, different clinical trials aimed at testing the efficacy of dasatinib and ruxolitinib are currently ongoing (Table 4).

Given the importance of MRD status as prognostic factor in ALL the role of Ph-like status has been investigated in the context of MRD-driven protocols, with conflicting results. Roberts et al.[57] reported in a pediatric cohort that an effective MRD-oriented risk-directed therapy can provide no differences in prognosis compared with other B-ALL subtypes when treated with intensive therapies. Opposite results were documented by Heatley et al.[118] who demonstrated that, despite a risk-adjusted treatment approach, a higher rate of relapse was recorded in patients who were retrospectively identified as Ph-like.

\section{Down syndrome ALL}

Children with Down syndrome (DS) have a 20 -fold increased risk of developing ALL. They account for $3 \%$ of all ALL cases with almost exclusively B-cell precursor immunophenotype. Although the etiology of this highrisk ALL remains largely unclear, recently mutations in JAK2, NRAS and KRAS genes, overexpression of CRLF2 and several other genetic alterations including IKZF1 deletion, PAX5 deletion, ETV6-IGH rearrangement have been identified in this setting and have emphasized the genetic heterogeneity of DSALL. Furthermore, studies on the effect of trisomy of Hmgn1 and Dyrk1a genes on B-cell development have shed significant new lights on the disease process[119].

Standard therapies were generally used for DS-ALL, but the unique toxicity profile of DS-ALL patients is still a challenge. Both the COG high-risk ALL study, AALL0331, which included prednisone or dexamethasone, vincristine, PEG-asparaginase and daunorubicin, and the standard-risk study, AALL0932, which provided dexamethasone, vincristine and PEG-asparaginase, showed a high mortality rate during the induction phase in patients with DS[17,119]. After the addition of extensive supportive care guidelines and leucovorin rescue for intrathecal methotrexate administration, the mortality decreased in the AALL0932 protocol, but not in AALL0232. According to these studies, the 3-drug combination was provided as induction in DS-ALL patients enrolled in the successive COG high-risk protocol AALL1131.

In contrast, the Ponte di Legno (PdL) study did not find any significant differences between 3-drug and 4drug induction, in treatment-related mortality (TRM), suggesting that anthracyclines do not influence the TRM[120]. Other important information coming from the PdL study is that the TRM in DS-ALL patients was observed not only during induction, but also in other phases of treatment, including maintenance therapy, that rarely causes death in ALL patients without DS[120]. The DFCI ALL Consortium protocols 00-001 and 05-001 proposed the same risk-stratified ALL therapy for children and adolescents with or without DS, 
without protocol-defined dose reductions or modifications for patients with DS, except for additional leucovorin after intrathecal methotrexate[121]. None of the DS-ALL patients showed induction failure or death; the proportion of B-precursor-ALL patients with high MRD level $(\geq 0.001 \%)$ at the end of induction therapy was comparable between the two groups (DS-ALL: $11 \%$ vs non-DS-ALL: $9 \% ; p=0.734$ ). However, in this study, patients with DS-ALL had significantly higher rates of infections, mucositis $(52 \%$ vs $12 \%$; $p<$ $0.001)$, seizures ( $16 \%$ vs $5 \% ; p=0.01$ ) and non-CNS thrombosis ( $18 \%$ vs $8 \% ; p=0.036)$ compared to the non-DS-ALL group. No significant differences in asparaginase-related toxicities (pancreatitis, allergy) between the two groups were documented[121].

Overall, the outcome of DS-ALL patients is worse than that of the general pediatric population. This difference is predominately correlated with therapy-related toxicities and with a higher relapse rate[120.

Whitlock et al.[122] and PdL investigators[120] reported that the $\mathrm{NCl}$ risk criteria did not predict the relapse risk in children with DS-ALL. However, in a multivariable model, DS-ALL children aged between 1 and 6 years with presenting $\mathrm{WBC}<10 \times 10^{9} / \mathrm{l}$, seem to represent a low risk group with a significant higher EFS (78\%), lower cumulative risk of relapse and lower 2-year TRM.

Future strategies to improve outcomes in DS-ALL should include better supportive care and decreased doses of chemotherapy especially in newly identified good-prognosis subgroups.

Several novel strategies including targeted therapies might help to improve outcomes in this population. Blinatumomab, a immunomodulatory agent (a CD19/CD3 bispecific antibody) and the anti-CD19 chimeric antigen receptor (CAR) T-cell therapy CTL019 have demonstrated, in a limited number of relapsed/refractory DS patients with ALL, high rates of $C R$ and a manageable safety profile, similar to children without DS (COG ALL1731 and multicenter ELIANA and ENSIGN trials[123,124]. Further exploration] of these new therapies, as an alternative to HSCT in children with relapsed/refractory DS ALL is warranted. Other potential new therapies include those that target JAK2 or $m T O R$, whose pathways are activated in the majority of DS-ALL cases. Investigational agents include JAK inhibitors, such as ruxolitinib and momelotinib, or mTOR inhibitors including temsirolimus and everolimus[125].

\section{Infant ALL}

Infant ALL is a rare serious disorder diagnosed in children with less than one year of age. ALL in infants has a significantly lower incidence than in children aged between 1 and 14 years old, and shows more aggressive features compared to older children[126]. The biological profile is quite different, characterized by balanced chromosome translocations involving KMT2A gene in $70-80 \%$ of cases, a very immature B-cell phenotype (pro-B), the co-expression of myeloid markers and a high tumor burden at diagnosis[126]. All these features negatively influence the prognosis in this subgroup. Recently, an association of the presence of KMT2A rearrangements (KMT2A-r) with an overexpression of the fms related tyrosine kinase (FLT3) gene was reported[126,127]. Andersson et al reported an association of KMT2A and mutations with KRAS and 
FLT3, using whole-genome or whole-exome sequencing[128]. The importance of these mutations in infant ALL has also been demonstrated in the clinical setting. Two independent cohorts including the large interfant-99 study reported that RAS mutations were independent adverse prognostic predictors[126]. In addition, FLT3 overexpression may confer especially poor prognosis in KMT2A-r patients. It has been reported in literature the occurrence of FLT3 mutation associated to KMT2A-r ALL and hyperdiploid cases. Considering the unusual expression of FLT3 in these patients, the COG AALL6631 trial, incorporated FLT3inhibitor (Lestaurtinib) as target agent in front-line treatment. Unfortunately this trial failed to demonstrate the benefit of additioning the FLT3-inhibitor[126]. However, those patients whose leukemia cells were sensitive to ex-vivo FLT3-inhibitor induced toxicity, did benefit from the addition of lestaurtinib[129].

Infants are generally treated differently than older children. The evidences of an in vitro sensitivity of lymphoblasts to cytarabine[130] has led to the development of protocols including this drug in the early phases of treatment. Recently, cooperative groups such as Interfant in Europe, COG in North America and Japan Association of Childhood Leukemia Study Group (JPLSG) in Japan have conducted three infants specific trials (Interfant-06, COG-AALL0631 and MLL-10)[126,131]. All of them adopted a common induction strategy based on the treatment schedule of the Interfant-99[126]; a risk-adapted strategy considering the KMT2A rearrangements status for the patient's stratification was also applied. The Interfant-99 treatment schedule included drugs used for ALL and acute myeloid leukemia and enrolled 483 infants. The induction phase consisted of dexamethasone, vincristine, daunorubicin and native E coli asparaginase with the addition of low-dose cytarabine preceded by a 7-day prednisone pre-phase. Based on day 8 prednisone response, all patients were stratified in two risk categories (standard and high risk). The CR was achieved in 93.9\% of patients at the end of the induction. The 5-year OS and EFS were $55.2 \%$ and $46.1 \%$, respectively[126,130,132]. In the randomized Interfant-06 trial, the backbone of the previous Interfant trial was maintained; 651 infants were enrolled. During the consolidation course, a randomized arm comparing myeloid-type chemotherapy and a lymphoid-type chemotherapy was introduced. The results of this trial did not show significantly higher survival rate with the introduction of an early intensification; the 6-year OS and EFS were $58.2 \%$ and $46.1 \%$, respectively. The CR rate at the end of the induction was $92.6 \%$. The relapse rate was $37.5 \%$. Interfant-06 trial confirmed the negative prognostic role of KMT2A, demonstrating that children with germline $M L L$ presented a better survival[131].

In recent years, preclinical research has shown a potential use of demethylating agents and histone deacetylase inhibitors in patients with KMT2A rearrangements[127,130]. Immunotherapy such as blinatumomab and CAR T cells is currently under investigation, and some case reports show an intriguing antileukemic role in this setting[131,132]. The COG and Interfant study groups are currently assessing the safety and feasibility of azacytidine and blinatumomab in the standard infant backbone therapy[127,131].

\section{Expert opinion}


The current induction treatment in pediatric ALL provides the use of vincristine corticosteroids asparaginase and anthracycline in the first phase, adding cyclophosphamide, cytarabine and methotrexate in the post-remission intensification phase. Through the use of these drug combinations, about $95 \%$ of children with ALL achieve a CR. Some clinical/biological characteristics at diagnosis and the MRD level detected by multiparametric flow cytometry and molecular techniques after induction, may significantly influence the prognosis in this setting. To date, the main challenge in selecting the proper induction strategy is to identify children with a low risk of relapse at an early stage, for whom a de-intensification of treatments is conceivable, thereby diminishing the potential treatment-related toxicities and induction mortality rate. On the contrary, in patients who present unfavorable characteristics at baseline, induction treatments should be intensified earlier in an attempt to determine a higher rate of CR associated with negative levels of MRD.

The treatment of AYA patients diagnosed with ALL represents another arduous challenge for the clinical oncologists. Although certain treatment-related toxicities are more frequent in AYA patients compared to children, emerging clinical evidence suggests that high-intensity pediatric induction and consolidation regimens are not only feasible in the AYA population, but also produce higher rates of response and outcome compared to adult protocols. As is the case in pediatrics, the effective management of treatmentrelated toxicities is crucial to ensure that AYAs receive the full benefit from ALL therapy. The ongoing developments of novel asparaginase preparations, such as pegylated recombinant Erwinia-derived asparaginase (PEG-crisantaspase) and red blood-cell encapsulated asparaginase, also might reduce immunogenicity and increase the overall length of asparagine depletion.

The TKI therapy has revolutionized induction approaches in children with Ph+ ALL. Outcomes of these patients have become more favorable, showing survival rates very close to those reported in Ph- ALL. Since a high portion of children achieves a negative MRD with current therapeutic approaches, the role of HSCT in $\mathrm{Ph}+\mathrm{ALL}$ patients remains an intriguing issue. The question is whether HSCT may currently be reserved only for high-risk patients, defined as those who are still MRD positive after induction and consolidation, those who harbor $A B L 1$ mutations or additional genomic lesions associated with poor prognosis.

The role of the Ph-like status in MRD-driven clinical trials is still unclear. A more effective approach could include the introduction of targeted therapies in patients with persistent MRD after the first consolidation, restricting the use of sophisticated diagnostic procedures aimed at the identification of targetable lesions in a small subgroup of patients. Different therapeutic options may be considered, such as TKIs or JAK inhibitors, and prospective trials now ongoing will better clarify the impact of these molecules on the achievement of a negative MRD and identify patients requiring HSCT in this setting.

To data, the induction modality of treatment in Infants and DS-ALL remains controversial. Hopefully, new evidence on the biological disease profile will provide new therapeutic strategies thereby improving outcomes in this setting. 


\section{Funding}

This paper was not funded.

\section{Declaration of interest}

S Chiaretti is on the advisory board for Amgen, Incyte, Shire and Pfizer. The authors have no other relevant affiliations or financial involvement with any organization or entity with a financial interest in or financial conflict with the subject matter or materials discussed in the manuscript apart from those disclosed.

\section{Reviewer Disclosures}

Peer reviewers on this manuscript have no relevant financial or other relationships to disclose.

\section{References}

Papers of special note have been highlighted as:

* of interest

** of considerable interest

1. Gaynon PS, Angiolillo AL, Carroll WL, et al. Long-term results of the children's cancer group studies for childhood acute lymphoblastic leukemia 1983-2002: a Children's Oncology Group Report. Leukemia. 2010; 24(2): 285-297.

2. Cooper LS, and Brown PA. Treatment of Pediatric Acute Lymphoblastic Leukemia. Pediatr Clin North Am. 2015; 62(1): 61-73.

3. Pui $\mathrm{CH}$, Yang JJ, Bhakta N, Rodriguez-Galindo C. Global efforts toward the cure of childhood acute lymphoblastic leukemia. Lancet Child Adolesc Health. 2018; 2(6): 440-454.

4. Kato M, Manabe A. Treatment and biology of pediatric acute lymphoblastic leukemia. Pediatr Int. 2018; 60(1): 4-12.

5. Moorman AV, Robinson $\mathrm{H}$, Schwab $\mathrm{C}$, et al. Risk-directed treatment intensification significantly reduces the risk of relapse among children and adolescents with acute lymphoblastic leukemia and intrachromosomal amplification of chromosome 21: a comparison of the MRC ALL97/ 99 and UKALL2003 trials. J Clin Oncol. 2013; 31(27): 33893396.

6. *Conter V, Bartram CR, Valsecchi MG, et al. Molecular response to treatment redefines all prognostic factors in children and adolescents with B-cell precursor acute lymphoblastic leukemia: results in 3184 patients of the AIEOP BFM ALL 2000 study. Blood. 2010; 115(16): 
3206-3214.(multicenter prospective study on the prognostic impact of minimal residual disease in childhood ALL)

7. Schrappe $M$, Valsecchi $M G$, Bartram $C R$, et al. Late $M R D$ response determines relapse risk overall and in subsets of childhood T-cell ALL: results of the AIEOP-BFM-ALL 2000 study. Blood. 2011; 118(8): 2077-2084.

8. Conter V, Valsecchi MG, Buldini B, et al. Early T-cell precursor acute lymphoblastic leukemia in children treated in AIEOP centres with AIEOP-BFM protocols: a retrospective analysis. Lancet Haematol. 2016; 3(2): 2352-3026.

9. Coustan-Smith E, Mullighan CG, Onciu M, et al. Early T-cell precursor leukaemia: a subtype of very high-risk acute lymphoblastic leukaemia. Lancet Oncol. 2009; 10(2): 147-156.

10. Borowitz MJ, Devidas M, Hunger SP, et al. Children's Oncology Group. Clinical significance of minimal residual disease in childhood acute lymphoblastic leukemia and its relationship to other prognostic factors: a Children's Oncology Group study. Blood. 2008; 111(15): 54775485.

11. *Biondi A, Gandemer V, De Lorenzo P, et al. Imatinib treatment of paediatric Philadelphia chromosome-positive acute lymphoblastic leukaemia (EsPhALL2010): a prospective, intergroup, open-label, single-arm clinical trial. Lancet Haematol. 2018; 5(12): e641e652. (prospective single-arm clinical trial on continuous imatinib throughout chemotherapy in $\mathrm{Ph}+$ childhood ALL)

12. Pui $\mathrm{CH}$, Pei D, Raimondi SC, et al. Clinical impact of minimal residual disease in children with different subtypes of acute lymphoblastic leukemia treated with response-adapted therapy. Leukemia. 2017; 31: 333-339.

13. Pui $\mathrm{CH}$; Pei $\mathrm{D}$, Coustan-Smith $\mathrm{E}$, et al. Clinical utility of sequential minimal residual disease measurements in the context of risk-based therapy in childhood acute lymphoblastic leukemia: a prospective study. Lancet Oncol. 2015; 16(4): 465-474.

14. Vora A, Goulden N, Mitchell C, Goulden N, Richards S. Improved outcome for children and young adults with T-cell acute lymphoblastic leukemia (ALL): results of the United Kingdom Medical Research Council (MRC) trial UKALL 2003. Blood, ASH annual Meeting 2008. Abs. 112: 908.

15. Vora A, Goulden N, Wade R, et al. Treatment reduction for children and young adults with low-risk acute lymphoblastic leukaemia defined by minimal residual disease (UKALL 2003): a randomized controlled trial. Lancet Oncol. 2013; 14: 119-209.

16. Veerman AJ, Hahlen K, Kamps WA, et al. High cure rate with a moderately intensive treatment regimen in non-high-risk childhood acute lymphoblastic leukemia. Results of protocol ALL VI from the Dutch Childhood Leukemia Study Group. J Clin Oncol. 1996; 14(3): 911-918. 
17. Maloney KW, Devidas M, Wang C, et al. Outcome of children with standard-risk B-cell acute lymphoblastic leukemia: results of Children's Oncology Group Trial AALL0331. J Clin Oncol. 2019; Dec 11 [Epub ahead of print].

18. *Schrappe M, Hunger SP, Pui $\mathrm{CH}$, et al. Outcomes after induction failure in childhood acute lymphoblastic leukemia. N Engl J Med. 2012; 366(15): 1371-1381. (extensive retrospective study in children enrolled in 14 cooperative trials investigating the prognostic features for induction failure)

19. Bhutani M, Kumar L, Vora A, et al. Randomized study comparing 4'-epidoxorubicin (epirubicin) versus doxorubicin as part of induction treatment in adult acute lymphoblastic leukemia. Am J Hematol. 2002; 71(4): 241-247.

20. Leblanc T, Auclerc MF, Cornu G, et al. Randomized study with idarubicine (IDR) versus daunorubicine (DNR) for induction treatment in intermediate risk acute lymphoblastic leukemia in childhood. Proceeding of the American Association for Cancer research.1996; 37: 171.

21. Yetgiu S, Obek NY, Masera G, et al. for Childhood Acute Lymphoblastic leukemia Collaborative Group (CALLCG). Beneficial and harmful effects of anthracyclines in the treatment of childhood acute lymphoblastic leukemia: a systemic review and meta-analysis. Br J Haematol. 2009; 145(3): 776-788.

22. Conter V, Aricò $M$, Basso $G$, et al. Long-term results of the Association of Pediatric Hematology Oncology (AIEOP) studies 82, 87, 88, 91 and 95 for childhood acute lymphoblastic leukemia. Leukemia. 2010; 24: 255-254.

23. ${ }^{* *}$ Vora A, Goulden N, Mitchell C, et al. Augmented post-remission therapy for a minimal residual disease-defined high-risk subgroup of children and young people with clinical standard-risk and intermediate-risk acute lymphoblastic leukemia (UKALL 2003): a randomized controlled trial. Lancet Oncol. 2014; 15(8): 809-818. (prospective randomized trial evaluating the role of MRD-based risk stratification in standard-risk childhood ALL)

24. Jeha S, Pui CH. Risk-adapted treatment of pediatric acute lymphoblastic leukemia. Haematol Oncol Clin. 2009; 23: 973-990.

25. Groninger E, Meeuwsen-de Boer T, Koopmans $P$, et al. Pharmacokinetics of vincristine monotherapy in childhood acute lymphoblastic leukemia. Eur J Cancer. 2005; 41(81): 98-103.

26. Heffner L. A new formulation of vincristine for acute lymphoblastic leukemia. Clin Adv Hematol Oncol. 2011; 9(4): 314-316.

27. Lavoie Smith EM, Li L, Chiang C, et al. Patterns and severity of vincristine-induced peripheral neuropathy in children with acute lymphoblastic leukemia. J Peripher Nerv Syst. 2015; 20: 3746. 
28. Lehtinen SS, Huuskonen UE, Harila-Sahari AH, et al. Motor nervous system impairment persists in long-term survivors of childhood acute lymphoblastic leukemia. Cancer.2002; 94: 2466-2473.

29. Sajdyk TJ, Boyle FA, Foran KS, et al. Obesity as a potential risk factor for vincristine-induced peripheral neuropathy. J Pediatr Hematol Oncol. 2019 Epub ahead of print].

30. Ringler I, West K, Dulin WE, Boland EW. Biological potencies of chemically modified adrenocorticosteroids in rat and man. Metabolism. 1964; 13: 37-44.

31. Kaspers GJ, Veerman AJ, Popp-Snijders C, et al. Comparison of antileukemic activity in vitro of dexamethasone and prednisolone in childhood acute lymphoblastic leukemia. Med Pediatr Oncol. 1996; 27: 114-121.

32. Balis FM, Lester CM, Chrousos GP, et al. Differences in cerebrospinal fluid penetration of corticosteroids: possible relationship to the prevention of meningeal leukemia. J Clin Oncol. 1987; 5(2): 2012-2017.

33. Jones B, Freeman Al, Shuster JJ, et al. Lower incidence of meningeal leukemia when prednisone is replaced by dexamethasone in the treatment of acute lymphoblastic leukemia. Med Pediatr Oncol. 1991; 19(4): 269-275.

34. Bostrom BC, Sensel MR, Sather HN, et al. Dexamethasone versus prednisone and daily oral versus weekly intravenous mercaptopurine for patients with standard-risk acute lymphoblastic leukemia: a report from the Children's Cancer Group. Blood. 2003; 101(10): 3809-3816.

35. Bartram J, Wade R, Vora A, et al. Excellent outcome of minimal residual disease-defined lowrisk patients is sustained with more than 10 years follow-up: results of UK pediatric acute lymphoblastic leukemia trials 1997-2003. Arch Dis Child. 2016; 101: 449-454.

36. DNofia $A M$, Seif $A E$, Devidas $M$, et al. Cost comparison by treatment arm and center-level variations in cost and inpatient days on the phase III high-risk B acute lymphoblastic leukemia trial AALL0232. Cancer Med.2018; 7(1): 3-12.

37. Moricke A, Zimmermann $M$, Valsecchi MG, et al. Dexamethasone vs prednisone in induction treatment of pediatric ALL: results of the randomized trial AIEOP-BFM ALL 2000. Blood. 2016; 127(17): 2101-2012.

38. Hofmans M, Suciu S, Ferster A, et al. Results of successive EORTC-CLG 58881 and 58951 trials in pediatric T-cell acute lymphoblastic leukemia (ALL). Br J Haematol. 2019; 186: 741-753.

39. Rizzari C, Conter V, Stary J, et al. Optimizing asparaginase therapy for acute lymphoblastic leukemia. Curr Opin Oncol. 2013; Suppl1: S 1-9.

40. Asselin BL, Whitin JC, Coppola DJ, et al. Comparative pharmacokinetic studies of three asparaginase preparation. J Clin Oncol. 1993; 11: 1780-1786. 
41. Vieira Pinheiro JP, Ahlke E, Nowak-Gottl U, et al. Pharmacokinetic dose adjustment of Erwinia asparaginase in protocol II of the pediatric ALL/NHL-BFM treatment protocols. Br J Haematol. 1999; 104: 313-320.

42. Klug Albertsen $B$, Schroder $H$, Jakobsen $P$, et al. Monitoring Erwinia asparaginase therapy in childhood ALL in the Nordic countries. Br J Clin Pharmacol. 2001; 52: 433-437.

43. Moghrabi A, Levy DE, Asselin B, et al. Results of the Dana-Farber Cancer Institute ALL Consortium Protocol 95-01 for children with acute lymphoblastic leukemia. Blood. 2007; 109: 896-904.

44. Duval M, Suciu S, Ferster A, et al. Comparison of Escherichia coli asparaginase with Erwiniaasparaginase in the treatment of childhood lymphoid malignancies: results of a randomized European Organisation for Research and Treatment of Cancer-Children's Leukemia Group phase 3 trial. Blood. 20012; 99: 2734-2739.

45. Hofmans M, Suciu S, Ferster A, et al. results of successive EORTC-CLG 58881 and 58951 trials in pediatric T-cell acute lymphoblastic leukemia (ALL). Br J Haematol. 2019; 186: 741-753.

46. Avramis VI, Sencer S, Periclou AP, et al. A randomized comparison of native Escherichia coli asparaginase and polyethylene glycol conjugated asparaginase for treatment of children with newly diagnosed standard-risk acute lymphoblastic leukemia: a Children's Cancer Group study. Blood. 2002; 99: 1986-1994.

47. Zalewska-Szewczyk B, Andrzejewski W, Mlynarski W, et al. The antiasparagines antibodies correlate with L-asparagines activity and may affect clinical outcome of childhood acute lymphoblastic leukemia. Leuk Lymphoma. 2007; 48: 931-936.

48. Panosyan EH, Seibel NL, Martin-Aragon S, et al. Asparaginase antibody and asparaginase activity in children with higher-risk acute Iymphoblastic leukemia: Children's Cancer Group Study CCG-1961. J Pediatr Hematol Oncol. 2004; 26: 217-226.

49. Burke MJ, Rheingold SR. Differentiating hypersensitivity versus infusion-related reactions in pediatric patients receiving intravenous asparaginase therapy for acute lymphoblastic leukemia. Leuk Lymphoma. 2017; 58(3): 540-551.

50. Vrooman LM, Supko JG, Neuberg DS, et al. Erwinia asparaginase after allergy to E. coli asparaginase in children with acute lymphoblastic leukemia. Pediatr Blood Cancer. 2010; 54: 199-205.

51. Basso G, Veltroni M, Valsecchi MG, et al. Risk of relapse of childhood acute lymphoblastic leukemia by flow cytometric measurement of residual disease on day 15 bone marrow. J Clin Oncol. 2009; 27(31): 5168-5174. 
52. **Campana D, Pui CH. Minimal residual disease-guided therapy in childhood acute lymphoblastic leukemia. Blood. 2017; 129(14): 1913-1918.(interesting review on the prognostic impact of MRD-guided therapy)

53. Mullighan CG, Jeha S, Pei D, et al. Outcome of children with hypodiploid ALL treated with riskdirected therapy based on MRD levels. Blood. 2015; 126: 2896-2899.

54. Yamaji K, Okamoto T, Yokota $S$, et al. Minimal residual disease-based augmented therapy in childhood acute lymphoblastic leukemia: a report from the Japanese Childhood Cancer and Leukemia Study Group. Pediatr Blood Cancer. 2010; 55:1287-1295.

55. Coustan-Smith E, Song G, Clark C, et al. New markers for minimal residual disease detection in acute lymphoblastic leukemia. Blood. 2011; 117(23): 6267-6276.

56. Pui $\mathrm{CH}$, Campana D, Pei $\mathrm{D}$, et al. Treating childhood acute lymphoblastic leukemia without cranial irradiation. N Engl Med. 2009; 360(26): 2730-2741.

57. Roberts KG, Pei D, Campana D, et al. Outcomes of children with BCR-ABL1-like acute lymphoblastic leukemia treated with risk-directed therapy based on the levels of minimal residual disease. J Clin Oncol. 2014; 32(27): 3012-3020.

58. Evans AE, Gilbert ES, Zandstra R. The increasing incidence of central nervous system leukemia in children (Children's Cancer Study Group A). Cancer. 1970; 26: 404.

59. Matloub Y, Lindemulder S, Gaynon PS, et al. Intrathecal triple therapy decreases central nervous system relapse but fails to improve event-free survival when compared with intrathecal methotrexate: results of the Children's Cancer group (CCG) 1952 study for standard-risk acute lymphoblastic leukemia, reported by the Children's Oncology Group. Blood. 2006; 108(4): 1165-1173.

60. Veerman AJ, Kamps WA, van den Berg H, et al. Dexamethasone-based therapy for childhood acute Iymphoblastic leukemia; results of the prospective Dutch Childhood Oncology Group (DCOG) protocol ALL-9 (1997-2004). Lancet Oncol. 2009; 10: 957-966.

61. "Jeha S, Pei D, Choi J, et al. Improved CNS control of childhood acute lymphoblastic leukemia without cranial irradiation: St Jude Total therapy Study 16. J Clin Oncol.2019; 37(35): 33773391.(intensification of intrathecal therapy during early induction, improves CNS control avoiding cranial irradiation)

62. Fiend BD, Shiller GJ. Closing the gap: novel therapies in treating acute lymphoblastic leukemia in adolescents and young adults. Blood Rev. 2018; 32(2): 122-129.

63. Siegel SE, Stock W, Johnson RH, et al. Pediatric-inspired treatment regimens for adolescents and young adults with Philadelphia chromosome-negative acute lymphoblastic leukemia: a review of advantages and challenges. JAMA Oncol. 2018; 4(5): 725-734. 
64. Larson RA, Dodge RK, Burns $\mathrm{CP}$, et al. A five-drug remission induction regimen with intensive consolidation for adults with acute lymphoblastic leukemia: cancer and leukemia group B study 8811. Blood. 1995; 85(8): 2025-2037.

65. Stock W, Johnson JL, Stone RM, et al. Dose intensification of daunorubicin and cytarabine during treatment of adult acute lymphoblastic leukemia: results of Cancer and Leukemia Group B Study 19802. Cancer. 2013; 119(1): 90-98.

66. Kantarjian HM, O'Brien S, Smith TL, et al. Results of treatment with hyper-CVAD, a doseintensive regimen, in adult acute lymphocytic leukemia. J Clin Oncol. 2000; 18(3):547-561.

67. Pulte D, Gondos A, Brenner H. Trends in 5- and 10-year survival after diagnosis with childhood hematologic malignancies in the United States, 1990-2004. J Natl Cancer Inst. 2008; 100(18): 1301-1309.

68. Smith MA, Seibel NL, Altekruse SF, et al. Outcomes for children and adolescents with cancer: challenges for the twenty-first century. J Clin Oncol. 2010; 28(15): 2625-2634.

69. Roberts KG, Li Y, Payne-Turner D, et al. Targetable kinase-activating lesions in Ph-like acute lymphoblastic leukemia. N Engl J Med. 2014; 371(11): 1005-1015.

70. Harrison CJ. Cytogenetics of paediatric and adolescent acute lymphoblastic leukaemia. $\mathrm{Br} \mathrm{J}$ Haematol. 2009; 144(2): 147-156.

71. Harrison CJ. Blood Spotlight on iAMP21 acute lymphoblastic leukemia (ALL), a high-risk pediatric disease. Blood. 2015; 125: 1383-1386.

72. Soulier J, Trakhtenbrot L, Najfeld V, et al. Amplification of band q22 of chromosome 21, including AML1, in older children with acute lymphoblastic leukemia: an emerging molecular cytogenetic subgroup. Leukemia. 2003; 17(8): 1679-1682.

73. Harrison CJ, Moorman AV, Schwab C, et al; Ponte di Legno International Workshop in Childhood Acute Lymphoblastic Leukemia. An international study of intrachromosomal amplification of chromosome 21 (iAMP21): cytogenetic characterization and outcome. Leukemia. 2014; 28(5): 1015-1021.

74. De Angelo DJ. The treatment of adolescents and young adults with acute lymphoblastic leukemia. Am Soc Hematol Edu Book. 2005; 2005: 123-130.

75. Asnafi V, Beldjord K, Libura M, et al. Age-related phenotypic and oncogenic differences in Tcell acute lymphoblastic leukemias may reflect thymic atrophy. Blood. 2004;104(13): 41734180.

76. Huguet F, Leguay T, Raffoux E, et al. Pediatric-inspired therapy in adults with Philadelphia chromosome-negative acute lymphoblastic leukemia: the GRAALL-2003 study. J Clin Oncol. 2009;27(6): 911-918. 
77. De Bont JM, Holt B, Dekker AW, et al. Significance difference in outcome for adolescents with acute lymphoblastic leukemia treated on pediatric versus adult protocols in the Netherlands. Leukemia. 2004; 18(12): 2032-2035.

78. Stock W, La M, Sanford B, et al. What determines the outcomes for adolescents and young adults with acute lymphoblastic leukemia treated on cooperative group protocols? A comparison of Children's Cancer Group and Cancer and Leukemia Group B studies. Blood. 2008; 112(5): 1646-1654.

79. Testi AM, Valsecchi MG, Conter V, et al. Differences in outcome of adolescents with acute lymphoblastic leukemia enrolled in pediatric (AIEOP) and adult (GIMEMA) protocols. Proceedings of American Society of Hematology $46^{\text {th }}$ annual meeting, San Diego, California, Dec 4-7 2004. Blood. 2004; 104(11): abstract 1954.

80. Ribera JM, Oriol A, Sanz MA, et al. Comparison of the results of the treatment of adolescents and young adults with standard-risk acute lymphoblastic leukemia with the Programa Español de Tratamiento en Hematología pediatric-based protocol ALL-96. J Clin Oncol. 2008;26(11): 1843-1849.

81. Toft N, Birgens H, Abrahamsson J, et al. Results of NOPHO ALL2008 treatment for patients aged 1-45 years with acute lymphoblastic leukemia. Leukemia. 2018; 32(3): 606-615.

82. Boissel N, Auclerc H, Lherieter V, et al. Should adolescents with acute lymphoblastic leukemia be treated as old children or young adults? Comparison of comparison of the French FRALLE93 and LALA-94 trials. J Clin Oncol. 2003; 21(5): 774-780.

83. Burke MJ, Gossai N, Wagner JE, et al. Survival differences between adolescents/young adults and children with B precursor acute lymphoblastic leukemia after al logeneic hematopoietic cell transplantation. Biol Blood Marrow Transplant. 2013; 19(1): 138142.

84. Barry E, De Angelo DJ, Neuberg D, et al. Favorable outcome for adolescents with acute Iymphoblastic leukemia treated on Dana- Farber Cancer Institute Acute Lymphoblastic Leukemia Consortium Protocols. J Clin Oncol. 2007; 25(7): 813-819.

85. Huguet $F$, Chevret $S$, Leguay $T$, et al. Intensified therapy of acute lymphoblastic leukemia in adults: report of the randomized GRAALL-2005 clinical trial. J Clin Oncol. 2018; 36(24): 25142523.

86. Rytting ME, Jabbour EJ, Jorgensen JL, et al. Final results of a single institution experience with a pediatric-based regimen, the augmented Berlin-Frankfurt-Munster, in adolescents and young adults with acute lymphoblastic leukemia, and comparison to the hyper-CVAD regimen. Am J Hematol. 2016; 91: 819-823. 
87. Rijneveld AW, van der Holt B, Daenen SMGJ, et al. Intensified chemotherapy inspired by a pediatric regimen combined with allogeneic transplantation in adult patients with acute lymphoblastic leukemia up to the age of 40 . Leukemia. 2011; 25(11): 1697-1703.

88. Ramanujachar R, Richards S, Hann I, et al. Adolescents with acute lymphoblastic leukemia: outcome on UK national pediatric (ALL97) and adult (UKALLXII/E2993) trials. Pediatr Blood Cancer. 2007; 48(3): 254-261.

89. Rytting ME, Thomas DA, O'Brien SM, et al. Augmented Berlin-Frankfurt-Münster Therapy in Adolescents and Young Adults (AYA) with Acute Lymphoblastic Leukemia (ALL). Cancer. 2014; 120(23): 3660-3668.

90. Stock W, Douer D, De Angelo DJ, et al. Prevention and management of asparaginase/pegasparaginase-associated toxicities in adults and older adolescents: recommendations of an expert panel. Leuk Lymphoma. 2011; 52(12): 2237-2253.

91. Mitchell L, Hoogendoorn H, Giles AR, et al. Increased endogenous thrombin generation in children with acute lymphoblastic leukemia: risk of thrombotic complications in $\mathrm{L}$ Asparaginase-induced antithrombin III deficiency. Blood. 1994; 83(2): 386-391.

92. Payne JH, Vora AJ. Thrombosis in acute lymphoblastic leukemia. Br J Haematol. 2007; 138(4): 430-445.

93. Douer D, Aldoss I, Lunning MA, et al. Pharmacokinetics based integration of multiple doses intravenous pegaspargase in a pediatric regimen for adults with newly diagnosed acute lymphoblastic leukemia. J Clin Oncol. 2014; 32(9): 905-911.

94. Plourde PV, Jeha S, Hijiva N, et al. safety profile of asparaginase Erwinia chrysanthemi in a large compassionate use trial. Pediatr Blood Cancer. 2014; 61(7): 1232-1238.

95. Stock W, Luger SM, Advani AS, et al. Favorable outcomes for older adolescents and young adults (AYA) with acute lymphoblastic leukemia (ALL): early results of US Intergroup trial C10403.proccedings of American Society of Hematology $56^{\text {th }}$ Annual Meeting San Francisco California Dec 6-9, 2014. Blood. 124(21): abstract 796.

96. Bassan R, Spinelli O, Oldani E, et al. Improved risk classification for risk-specific therapy based on the molecular study of minimal residual disease (MRD) in adult acute lymphoblastic leukemia (ALL). Blood. 2009; 113(18): 4153-4162.

97. Nagafuji K, Mayamoto T, Eto T, et al. Monitoring of minimal residual disease (MRD) is useful to predict prognosis of adult patients with Ph-negative ALL: results of a prospective study (ALL MRD 2002 Study). J Hematol Oncol. 2013; 6(6): 14.

98. Faham M, Zheng J, Moorhead M, et al. Deep-sequencing approach for minimal residual disease detection in acute lymphoblastic leukemia. Blood. 2012; 120(26): 5173-5180. 
99. Malnassy G, Carlton V, Moorhead M, Faham M, Stock W. Comparison of next-generation sequencing and ASO-PCR methods for MRD detection in acute lymphoblastic leukemia. Haematologica. 2013; 98: 224-225.

100. Gökbuget N, Kneba M, Raff T, et al. German Multicenter Study Group for Adult Acute Lymphoblastic Leukemia. Adult patients with acute lymphoblastic leukemia and molecular failure display a poor prognosis and are candidates for stem cell transplantation and targeted therapies. Blood. 2012; 120(9): 1868-1876.

101. Aricò M, Valsecchi MG, Camitta B, et a. Outcome of treatment in children with Philadelphia chromosome-positive acute lymphoblastic leukemia. N Engl J Med. 2000; 342(14): 998-1006.

102. Aricò $M$, Schrappe $M$, Hunger $S P$, et al. Clinical outcome of children with newly diagnosed Philadelphia chromosome-positive acute lymphoblastic leukemia treated between 1995 and 2005. J Clin Oncol. 2010; 28: 4755-4761.

103. Bleckmann $K$ and Schrappe $M$. Advances in therapy for Philadelphia-positive acute lymphoblastic leukemia in childhood and adolescence. $\mathrm{Br} J$ Haematol. 2016; 172: 855-869.

104. Biondi A, Gunnar C, De Lorenzo P, et al. Long-term follow up of pediatric Philadelphia positive acute lymphoblastic leukemia treated with EsPhALL2004 study: high white blood cell count at diagnosis is the strongest prognostic factor. Haematologica. 2019; 104(1): e13-e16.

105. Schultz KR, Carroll A, Heerema NA, et al. Long-term follow-up of imatinib in pediatric Philadelphia chromosome-positive acute lymphoblastic leukemia: Children's Oncology group Study AALL0031. Leukemia. 2014; 28: 1467-1471.

106. Jeha $S$, Coustan-Smith $E$, Pei $D$, et al. Impact of tyrosine kinase inhibitors on minimal residual disease and outcome in childhood Philadelphia chromosome-positive acute lymphoblastic leukemia. Cancer. 2014; 120(10): 1514-1519.

107. Slayton WB, Schultz KR, Kairalla JA, et al. Dasatinib plus intensive chemotherapy in children, adolescents, and young adults with Philadelphia chromosome-positive acute lymphoblastic leukemia: results of Children's Oncology Group Trial ALL0622. J Clin Oncol. 2018; 36: 23062314.

108. Jabbour $\mathrm{E}$, Kantarjian $\mathrm{H}$, Ravandi $\mathrm{F}$ et al. Combination of hyper-CVAD with ponatinib as firstline therapy for patients with Philadelphia chromosome-positive acute lymphoblastic leukemia: a single-centre, phase2 study. Lancet Oncol. 2015; 16: 1547-1555.

109. Chiaretti S, Bassan R, Vitale A et al. A Dasatinib-Blinatumomab combination for the frontline treatment of adult Ph+ ALL patients. Updated results of the GIMEMA LAL 2116 D-ALBA trial; on behalf of GIMEMA Acute Leukemia Working Party. Proceedings of American Society of Hematology $61^{\text {st }}$ Annual Meeting Orlando, Florida Dec 7-10, 2019 (Abstract 740). 
110. Mulligan CG, Su X, Zhang J et al. Children's Oncology Group. Deletion of IKZ1 and prognosis in acute lymphoblastic leukemia. N Engl J Med. 2009; 360: 470-480.

111. Den Boer ML, van Slegtenhorst $M$, De Menezes RX et al. A subtype of childhood acute lymphoblastic leukemia with poor treatment outcome: a genome-wide classification study. Lancet Oncol. 2009; 10: 125-134.

112. Chiaretti S, Li X, Gentleman R et al. Gene expression profiles of B-lineage adult acute lymphocytic leukemia reveal genetic patterns that identify lineage derivation and distinct mechanisms of transformation. Clin Cancer Res. 2005; 11: 7209-7219.

113. Roberts KG, Gu Z, Payne-Turner D et al. High frequency and poor outcome of Philadelphia chromosome-like acute lymphoblastic leukemia in adults. J Clin Oncol. 2017; 35: 394-401.

114. Jain $\mathrm{N}$, Roberts $\mathrm{KG}$, Jabbour $\mathrm{E}$ et al. Ph-like acute lymphoblastic leukemia: a high-risk subtype in adults. Blood. 2017; 129: 572-581.

115. Herold T, Schneider S, Metzeler KH et al. Adults with Philadelphia chromosome-like acute lymphoblastic leukemia frequently have IGH-CRLF2 and JAK2 mutations, persistence of minimal residual disease and poor prognosis. Haematologica. 2017; 102: 130-138.

116. Kobayashi K, Miyagawa N, Mitsui K, et al. TKI dasatinib monotherapy for a patient with Phlike ALL bearing ATF1P/PDGFRB translocation. Pediatr Blood Cancer. 2015; 62(6): 1508-1060.

117. Jain N, Jabbour EJ, McKay $\mathrm{PZ}$, et al. Ruxolitinib or dasatinib in combination with chemotherapy for patients with relapsed/refractory Philadelphia (Ph)-like acute lymphoblastic leukemia: a phase I-II trial. Blood. 2017; 130(Suppl 1): 1322.

118. Heatley SL, Sadras T, Kok CH et al. High prevalence of relapse in children with Philadelphialike acute lymphoblastic leukemia despite risk-adapted treatment. Haematologica. 2017; 102: e490-493.

119. Maloney KW, Wood B, Whitlock JA, et al. Event free (EFS) and overall survival (OS) for children with Down syndrome (DS) and B-lymhoblastic leukemia in Children's Oncology Group (COG) trials AALL0232 and AALL0331. Pediatric Blood \& Cancer. 2014; 61(S1): S4. abstract \#4009.

120. Buitenkamp TD, Izraeli S, Zimmermann $M$, et al. Acute lymphoblastic leukemia in children with Down syndrome: a retrospective analysis from the Ponte di Legno study group. Blood. 2014; 123(1): 70-77.

121. Athale UH, Puligandla $M$, Stevenson $K E$, et al. Outcome of children and adolescents with Down syndrome treated on Dana-Farber Cancer Institute Acute Lymphoblastic Leukemia Consortium protocols 00-001 and 05-001. Pediatr Blood Cancer. 2018; 65(10): e27256. 
122. Whitlock JA, Sather HN, Gaynon P, et al. Clinical characteristics and outcome of children with Down syndrome and acute lymphoblastic leukemia: a Children's Cancer Group study. Blood. 2005; 106: 4043-4049.

123. Laetsch TW, Maude SL, Grupp SA, et al. CTL019 therapy appears safe and effective in pediatric patients with Down Syndrome with relapsed/refractory $(r / r)$ acute lymphoblastic leukemia. Blood. 2017; 130 (Suppl. 1): 1280.

124. Annesley $C E$, Brown $P$. Novel agents for the treatment of childhood acute leukemia. Therapeutic Advances in Hematology. 2015; 6(2): 61-79.

125. Tasian SK, Doral MY, Borowitz MJ, et al. Aberrant STAT5 and PI3K/mTOR pathway signaling occurs in human CRLF2-rearranged B-precursor acute lymphoblastic leukemia. Blood. 2012; 120(4): 833-842.

126. Pieters $R$, Schrappe $M$, De Lorenzo $P$, et al. A treatment protocol for infants younger than 1 year with acute lymphoblastic leukemia (Interfant-99): an observational study and a multicentric randomized trial. Lancet. 2007; 370(9583): 240-250.

127. Brown P, Pieters R, Biondi A. How I treat infant leukemia. Blood. 2019; 133(3): 205-214.

128. Andersson AK, Ma J, Wang J, et al. The landscape of somatic mutations in infant MLLrearranged acute lymphoblastic leukemias. Nat Genet. 2015; 47(4): 330-337.

129. Brown AP, Kauralla J, Hilden JM, et al. FLT3 inhibitor correlative laboratory assays impact outcomes in KMT2A-rearranged infant acute lymphoblastic leukemia (ALL) patients treated with lestaurtinib: AALL0631, a Children's Oncology Group Study. Blood. 2019; 134 (suppl. 1): 1293.

130. Kotecha RS, Gottardo NG, Kees UR, Cole CH. The evolution of clinical trials for infant acute lymphoblastic leukemia. Blood Cancer J. 2014; 4: e200.

131. Peters $R$, De Lorenzo $P$, Ancliffe $P$, et al. Outcome of infants younger than 1 year with acute lymphoblastic leukemia treated with the Interfant 06 protocol: results from an international phase 3 randomized study. J Clin Oncol. 2019; 37(25): 2246-2256.

132. Brown P. Treatment of infant leukemia: challenges and promise. Hematology AM Soc Hematol Educ Program 2013. 2013: 596-600. 
Table 1. Selected pediatric ALL random studies evaluating type of aparaginase and steroids

\begin{tabular}{|c|c|c|c|c|c|c|c|c|c|c|c|c|c|}
\hline Author & Protocol & & $\begin{array}{l}\text { Age } \\
\text { (yrs } \\
\text { ) }\end{array}$ & $\begin{array}{l}\text { Risk } \\
\text { group }\end{array}$ & $\begin{array}{l}\text { N. } \\
\text { pts }\end{array}$ & Random & $\begin{array}{l}\text { Coagulatio } \\
\mathrm{n} \\
\text { abnormaliti } \\
\text { es (\%) }\end{array}$ & $\begin{array}{l}\text { Toxicity } \\
\text { (\%) }\end{array}$ & $\begin{array}{l}\text { Asparagina } \\
\text { se } \\
\text { antibodies } \\
(\%)\end{array}$ & $\begin{array}{l}\text { No } \\
\text { CR } \\
(\%)\end{array}$ & $\begin{array}{l}\text { Relaps } \\
\text { e (\%) }\end{array}$ & $\begin{array}{l}\text { EFS } \\
(\%)\end{array}$ & $\begin{array}{l}\text { OS } \\
(\%)\end{array}$ \\
\hline $\begin{array}{l}\text { Duval } \\
2002 .^{24}\end{array}$ & $\begin{array}{l}\text { EORTC- } \\
\text { CLG } \\
58881 \\
1990- \\
1993\end{array}$ & $\begin{array}{l}\text { ALL } \\
/ \\
\mathrm{LBL}\end{array}$ & $<18$ & All risks & 700 & $\begin{array}{l}{ }^{*} \text { E. coli } \\
\text { asp vs } \\
\text { Erwinia } \\
\text { asp }\end{array}$ & $\begin{array}{l}30.2 \% \quad p< \\
.0001 \\
11.9 \%\end{array}$ & - & - & $\begin{array}{l}2 \% \\
\text { p.03 } \\
8 \\
4.9 \%\end{array}$ & - & $\begin{array}{l}73.4 \\
\% \\
\text { p.000 } \\
4 \\
59.8\end{array}$ & $\begin{array}{l}83.9 \\
\% \\
\text { p.002 } \\
75.1 \\
\%\end{array}$ \\
\hline $\begin{array}{l}\text { Avramis } \\
2002 .^{26}\end{array}$ & $\begin{array}{l}\text { CCG } 1962 \\
1997- \\
1998\end{array}$ & ALL & $1-9$ & $\begin{array}{l}\text { Standard } \\
\text { risk }\end{array}$ & 118 & $\begin{array}{l}* * \text { PEG } \\
\text { vs } \\
\text { Native }\end{array}$ & NA & - & $\begin{array}{l}2 \% \\
\text { p.0009 } \\
26 \%\end{array}$ & & & $\begin{array}{l}85 \% \\
\text { NS } \\
78 \%\end{array}$ & - \\
\hline $\begin{array}{l}\text { Moghra } \\
\text { bi } \\
2006 .^{23}\end{array}$ & $\begin{array}{l}\text { DFCl 95- } \\
01 \\
1996- \\
2000\end{array}$ & ALL & $\begin{array}{l}0- \\
18\end{array}$ & All risks & 491 & $\begin{array}{l}* * * \text { Coli } \\
\text { asp vs } \\
\text { Erwinia } \\
\text { asp }\end{array}$ & - & $\begin{array}{l}24 \% \quad p \\
<0.1 \\
10 \%\end{array}$ & - & & $\begin{array}{l}10 \% \\
p<.02 \\
19 \%\end{array}$ & $\begin{array}{l}89 \% \\
\text { p.01 } \\
78 \%\end{array}$ & - \\
\hline $\begin{array}{l}\text { Moricke } \\
\text { 2016. }^{18}\end{array}$ & $\begin{array}{l}\text { AIEOP/BF } \\
\text { M } \\
\text { LAL 2000 } \\
2000- \\
2006\end{array}$ & ALL & $\begin{array}{l}1- \\
17\end{array}$ & All risks & $\begin{array}{l}372 \\
0\end{array}$ & $\begin{array}{l}{ }^{\circ} \text { Dexa } \\
\text { vs } \\
\text { PDN }\end{array}$ & - & $\begin{array}{l}0.5 \% \mathrm{p} \\
.022 \\
0.1 \% \\
\text { (Inducti } \\
\text { on } \\
\text { death) }\end{array}$ & & NS & $\begin{array}{l}10.8 \% \\
p<.000 \\
1 \\
15.6 \%\end{array}$ & $\begin{array}{l}83.9 \\
\% \\
\text { p.024 } \\
80.8 \\
\%\end{array}$ & $\begin{array}{l}90.3 \\
\% \\
\text { NS } \\
90.5 \\
\%\end{array}$ \\
\hline \multirow[t]{3}{*}{$\begin{array}{l}\text { Hoffma } \\
\text { ns } \\
2019 .^{25}\end{array}$} & $\begin{array}{l}\text { EORTC- } \\
\text { CLG } \\
58881 \\
1989- \\
1998\end{array}$ & $\begin{array}{l}\mathrm{T} \\
\mathrm{ALL}\end{array}$ & $<18$ & $\begin{array}{l}\text { Increase } \\
\text { d/ very } \\
\text { high risk }\end{array}$ & 303 & $\begin{array}{l}\text { Medac } \\
\text { asp } \\
\text { Non } \\
\text { Medac } \\
\text { asp } \\
\text { (no } \\
\text { Random } \\
\text { ) } \\
\end{array}$ & & - & - & - & $\begin{array}{l}22.5 \% \\
38.2 \%\end{array}$ & $\begin{array}{l}71.6 \\
\% \\
\text { p.001 } \\
5 \\
52.1 \\
\%\end{array}$ & $\begin{array}{l}77.7 \\
\% \\
\text { p.001 } \\
8 \\
59.6 \\
\%\end{array}$ \\
\hline & \multirow[t]{2}{*}{$\begin{array}{l}\text { EORTC- } \\
\text { CLG } \\
58951 \\
1998- \\
2008\end{array}$} & \multirow[t]{2}{*}{$\begin{array}{l}\mathrm{T} \\
\mathrm{ALL}\end{array}$} & \multirow[t]{2}{*}{$<18$} & \multirow[t]{2}{*}{$\begin{array}{l}\text { Average } \\
\text { risk } \\
\text { 2/very } \\
\text { high risk }\end{array}$} & 296 & $\begin{array}{l}\text { oo Dexa } \\
\text { vs }\end{array}$ & - & - & - & - & $\begin{array}{l}22.1 \% \\
19.2 \%\end{array}$ & $\begin{array}{l}71.3 \\
\% \\
\text { NS } \\
76.7 \\
\%\end{array}$ & $\begin{array}{l}74.2 \\
\% \\
\text { NS } \\
84.4 \\
\%\end{array}$ \\
\hline & & & & & 147 & $\begin{array}{l}\text { Prolong } \\
\text { ed asp } \\
\text { Short } \\
\text { asp }\end{array}$ & - & - & - & - & $\begin{array}{l}16.4 \% \\
17.6 \%\end{array}$ & $\begin{array}{l}82.9 \\
\% \\
\text { (DFS) } \\
\text { NS } \\
82.1 \\
\% \\
\text { (DFS) }\end{array}$ & $\begin{array}{l}87.4 \\
\text { NS } \\
91.9\end{array}$ \\
\hline
\end{tabular}

AIEOP: Associazione Italiana EmatoOncologia Pediatrica; ALL: acute lymphoblastic leukemia; Asp: Asparaginase; BFM: Berlin Frankfurt Munster; CCG: Children cancer group; CR: Complete remission; Dexa: Dexametasone; DFCI: Dana Farber Cancer Institute; DFS: Disease free survival; EFS: Event free survival; EORTC-CLG: European Organisation for Research and Treatment of Cancer-Children's Leukemia Group; LBL: Iymphoblastic lymphoma; OS: Overall survival; PEG: pegylated asparaginase.

* E. coli-or Erwinia asparaginase at the same dosage of $10.000 \mathrm{IU} / \mathrm{m}^{2}$ twice weekly

** PEG $2500 \mathrm{IU} / \mathrm{m}^{2} \mathrm{IM}$ on day 3 of induction and each DI phase or Native-asparaginase $6000 \mathrm{IU} / \mathrm{m}^{2} \mathrm{IM} 3$ times per week, for 9 doses in induction, and 6 doses in each DI phase.

*** Erwinia or E coli asparagianse $25.000 \mathrm{IU} / \mathrm{m}^{2}$

- Prednisone $\left(60 \mathrm{mg} / \mathrm{m}^{2} /\right.$ day) or dexamethasone $\left(10 \mathrm{mg} / \mathrm{m}^{2} /\right.$ day $)$

○Prednisolone $\left(60 \mathrm{mg} / \mathrm{m}^{2} /\right.$ day) or dexamethasone $\left(6 \mathrm{mg} / \mathrm{m}^{2} /\right.$ day) 
Table 2. Studies which enrolled AYAs on both pediatric and adult trials.

\begin{tabular}{|c|c|c|c|c|c|c|c|}
\hline Study & $\begin{array}{l}\text { Nof } \\
\text { pts }\end{array}$ & $\begin{array}{l}\text { Age } \\
\text { range }\end{array}$ & Adult protocol & $\begin{array}{l}\text { Pediatric } \\
\text { protocol }\end{array}$ & EFS & OS & CR \\
\hline De Bont et al. ${ }^{48}$ & 91 & $\begin{array}{l}15-18 \\
\text { years }\end{array}$ & HOVON ALL-5+ALL-18 (n=44) & $\begin{array}{l}\text { DCOG ALL6+9 } \\
\quad(n=47)\end{array}$ & $\begin{array}{c}34 \% \\
\text { vs } \\
69 \% \\
\end{array}$ & $\begin{array}{c}91 \% \\
\text { vs } \\
98 \% \\
\end{array}$ & $\begin{array}{c}38 \% \\
\text { vs } \\
79 \% \\
\end{array}$ \\
\hline Stock et al. ${ }^{49}$ & 321 & $\begin{array}{l}16-20 \\
\text { years }\end{array}$ & CALG8811+9111+9311+9511 $(n=124)$ & COG1882+1901 & $\begin{array}{c}34 \% \\
\text { vs } \\
63 \%\end{array}$ & $\begin{array}{c}46 \% \\
\text { vs } \\
67 \% \\
\end{array}$ & $\begin{array}{c}90 \% \\
\text { vs } \\
90 \% \\
\end{array}$ \\
\hline Testi et al. $^{50}$ & 245 & $\begin{array}{l}14-18 \\
\text { years }\end{array}$ & GIMEMA 0496+2000 & AIEOP 95+ 2000 & $\begin{array}{c}55 \% \\
\text { vs } \\
83 \% \\
\end{array}$ & $\begin{array}{c}71 \% \\
\text { vs } \\
80 \% \\
\end{array}$ & $\begin{array}{c}89 \% \\
\text { vs } \\
84 \% \\
\end{array}$ \\
\hline Boissel et al. $^{53}$ & 177 & $\begin{array}{l}15-20 \\
\text { years }\end{array}$ & FRALLE-93 $(n=77)$ & LALA-93 $(n=100)$ & $\begin{array}{c}41 \% \\
\text { vs } \\
67 \% \\
\end{array}$ & $\begin{array}{c}45 \% \\
\text { vs } \\
78 \% \\
\end{array}$ & $\begin{array}{c}83 \% \\
\text { vs } \\
94 \% \\
\end{array}$ \\
\hline $\begin{array}{c}\text { Ramanuijachar } \\
\text { et al. }\end{array}$ & 128 & $\begin{array}{l}15-17 \\
\text { years }\end{array}$ & UKAL 97/99 (n=61) & UKALL (n=67) & $\begin{array}{c}49 \% \\
\text { vs } \\
65 \% \\
\end{array}$ & $\begin{array}{c}56 \\
\text { vs } \\
71 \% \\
\end{array}$ & $\begin{array}{c}94 \% \\
\text { vs } \\
98 \% \\
\end{array}$ \\
\hline Rytting et al. $^{57}$ & 208 & $\begin{array}{l}13-40 \\
\text { years }\end{array}$ & Hyper-CVAD $(n=102)$ & $\operatorname{aBFM}(n=106)$ & $\begin{array}{c}53 \% \\
\text { vs } \\
55 \% \\
\end{array}$ & $\begin{array}{c}60 \% \\
\text { vs } \\
60 \% \\
\end{array}$ & $\begin{array}{c}98 \% \\
\text { vs } \\
93 \% \\
\end{array}$ \\
\hline Rytting et al. $^{60}$ & 156 & $\begin{array}{l}13-40 \\
\text { years }\end{array}$ & Hyper-CVAD (n=7 & $\operatorname{aBFM}(n=85)$ & $\begin{array}{c}66 \% \\
\text { vs } \\
70 \% \\
\end{array}$ & $\begin{array}{c}66 \% \\
\text { vs } \\
70 \% \\
\end{array}$ & $\begin{array}{c}99 \% \\
\text { vs } \\
94 \% \\
\end{array}$ \\
\hline
\end{tabular}

aBFM: augmented Berlin-Frankfurt-Munster; AIEOP: Associazione Italiana Ematologia ed Oncologia Pediatrica; CALG: Cancer and Leukemia Group; COG: Children's Oncology Group; CR: complete remission; DCOG: Dutch Childhood Cooperative Group; EFS: event-free survival; FRALLE: French Acute Lymphoblastic Leukemia study Group; LALA: GIMEMA: Gruppo Italiano Malattie Ematologiche dell'adulto; HOVON: Hemato-Oncologie for adults in Nederlands; OS: overall survival; UKALL: United Kingdom Acute Lymphoblastic Leukemia 
Table 3. Selected pediatric Ph+ ALL studies

\begin{tabular}{|c|c|c|c|c|c|c|c|c|}
\hline Author & Protocol & Period & TKI & Chemotherapy & $\begin{array}{l}\text { Age } \\
\text { (years) }\end{array}$ & N. patients & CR (\%) & HSCT (\%) \\
\hline $\begin{array}{l}\text { Aricò } \\
\text { 2000. }^{72}\end{array}$ & $\begin{array}{l}\text { International } \\
\text { multicenter } \\
\text { (Ponte di Legno) }\end{array}$ & 1985-1996 & No & $\begin{array}{l}\text { HR ALL } \\
\text { (Various) }\end{array}$ & $0.4-19.9$ & 326 & 81.9 & 45 \\
\hline $\begin{array}{l}\text { Aricò } \\
\text { 2010. }^{73}\end{array}$ & $\begin{array}{l}\text { International } \\
\text { multicenter }\end{array}$ & $1995-2005$ & No & $\begin{array}{l}\text { HR ALL } \\
\text { (Various) }\end{array}$ & $0.7-18$ & 610 & 89 & 60 \\
\hline $\begin{array}{l}\text { Biondi } \\
\text { 2019. }^{75}\end{array}$ & EsPhALL 2010 & 2010-2014 & $\begin{array}{l}\text { Imatinib } \\
\text { Day } 15\end{array}$ & HR BFM & $1-17$ & 155 & 100 & 38 \\
\hline $\begin{array}{l}\text { Slayton } \\
2018 .{ }^{78}\end{array}$ & $\begin{array}{l}\text { AALL0622 } \\
\text { COG }\end{array}$ & $2008-2012$ & $\begin{array}{l}\text { Dasatinib } \\
\text { Day } 15\end{array}$ & VHR COG & $1-18$ & 60 & 98 & 54 \\
\hline
\end{tabular}

ALL: acute lymphoblastic leukemia; BFM: Berlin-Frankfurt-Munster; COG: Children's Oncology Group; CR: complete remission; DFS: disease-free survival; EFS: event free survival; EsPhALL: European Intergroup of patients with Ph+ALL; HR: high-risk; HSCT: hematopoietic stem cell transplant; OS: overall survival; TKI: tirosin kinase inhibitor; VHR: very high-risk 
Table 4. Current clinical trials, phase $2 / 3$, including kinase inhibitors for the treatment of children and AYA with newly diagnosed Ph-like ALL

\begin{tabular}{|c|c|c|c|}
\hline Genetic marker & Age (years) & Clinical trial & Kinase inhibitor \\
\hline ABL class & $1-30$ & NCT01406756 (COG) & dasatinib \\
\hline & $1-18$ & NCT03117751 (SJCRH) & dasatinib \\
\hline CRLF2/JAK & $1-21$ & NCT02723994 (COG) & ruxolitinib \\
\hline & $1-18$ & NCT03117751 (SJCRH) & ruxolitinib \\
\hline
\end{tabular}

